\title{
AN INTEGRATED APPROACH FOR PREDICTING THE SHEAR CAPACITY OF FIBRE REINFORCED CONCRETE BEAMS
}

\author{
Joaquim A. O. Barros ${ }^{1}$; Stephen J. Foster ${ }^{2}$ \\ ${ }^{1}$ Full Professor, ISISE, Dep. Civil Eng. Minho University, Visiting Professorial Fellow of \\ UNSW Sydney, barros@ civil.uminho.pt, corresponding Author \\ ${ }^{2}$ Professor and Head, School of Civil and Environmental Engineering, UNSW Sydney, \\ Australia, $\underline{\text { s.foster@unsw.edu.au }}$
}

\begin{abstract}
:
This paper describes the development of an integrated design approach for determining shear capacity of flexurally reinforced steel fibre reinforced concrete members. The approach considers fibre distribution profile, fibre pull-out resistance and the modified compression field theory integrated using a comprehensive strategy. To assess the performance of the developed model, a database consisting of 122 steel fibre reinforced and prestressed concrete beams failing in shear was assembled from available literature. The model predictions were shown to correlate well with the test data. The performance of the analytical model was also compared to predictions attained by the two approaches recommended by the fib Model Code 2010, one based on an empirical equation and the other on the modified compression field theory approach. The predictive performance of the proposed approach was also assessed by using the Demerit Points Classification (DPC), being the prediction as better as lower is the total penalty points provided by the classification. The model developed in this paper demonstrated a superior performance to those of the Model Code, with a higher predictive performance in terms of safety and reliability.
\end{abstract}

Keywords: Fibre reinforced concrete, beams, shear, integrated shear model, unified variable engagement model. 


\section{Introduction}

The first fibre reinforced beams tested for shear were those of Batson et al. [1]. They investigated a range of fibre types and geometries, as well as span-to-depth ratios. Since this time, numerous studies have demonstrated that the presence of steel fibres increases the shear strength of concrete beams [2-26]. Even though the costs steel fibres may exceed substantially that of relatively cheap steel ligatures for the carrying of shear stress resultants, there is potential for significant savings in site labour costs. Whether or not fibres can replace conventional transverse steel bar reinforcement in reinforced concrete beams is a matter that needs to be addressed through analysis of experimental data and in models development.

For determining the reliability of various competing design models, a database of reliable experimental tests must first be established. One of early documented studies with an extensive data collection is that of Adebar et al. [26]. Their study identified 413 SFRC beams reported in the literature as being tested in shear, although many of the tests were limited by their flexural strength. Recent articles have been dedicated to prepare substantive test databases in this subject [27-30].

It is well recognized that the post-cracking tensile, or pull-out, response of fibre reinforcement embedded in cement based materials is the distinguishing characteristic defining performance in terms of serviceability (including stiffness), durability and strength of fibre-reinforced structural elements. This is represented by the stress-crack width relationship, $\sigma-w$. In structures governed by shear, fibre reinforcement increases the stiffness and strength of the shear stress transfer across cracks [31]; however, a methodology to capture the contribution of fibre reinforcement to shear strength enhancement is challenging.

Despite the high potential, a consensual modelling approach does not yet exist for predicting shear strength of fibre reinforced concrete (FRC) beams at high accuracy, where flexure is resisted primarily by bar reinforcement or tendons. While the models developed in this study are generic in their nature, and apply across the breadth of fibres produced of different materials, 
experimental testing to date of reinforced concrete FRC beams has almost exclusively been undertaken using steel fibres; these are herein termed R/SFRC beams.

Two approaches for the determination of the shear strength of R/SFRC are described in the fib Model Code 2010 [31]; the first has its basis in a Eurocode 2 empirical design strategy [6], the second using a philosophy founded from the modified compression field theory (MCFT) [27]. In this paper a physical-mechanical model is developed for assessing the strength of R/SFRC beams failing in shear. The approach integrates fibre orientation profile along the critical diagonal crack (CDC), the relevant pull-out mechanisms of steel fibres and the fundamental concepts of the MCFT. The models are compared to test data of 122 beams collected from the literature, and the results are reported herein.

\section{MC2010 Approaches for Shear Strength of R/SFRC Beams}

\subsection{Introduction}

The fib Model Code 2010 [31] outlines two approaches for determining the shear capacity of $\mathrm{R} / \mathrm{SFRC}$ beams. The first is based on a modification to the Eurocode model and the second is founded on the MCFT. The backgrounds of these two models are described briefly in this section.

\subsection{Approach based on the concept of residual flexural strength for FRC}

This approach, denoted in this paper as MC2010-EEN, is based on the empirical equation developed in [6]. By this approach, the shear resistance is obtained from [32]:

$$
V_{R d}=V_{R d, F}+V_{R d, s}
$$

where $V_{R d, F}$ and $V_{R d, s}$ are the components of shear carried by fibres and shear ligatures, respectively. The fibres component is given by:

$$
V_{R d, F}=\left\{\frac{0.18}{\gamma_{c}} k\left[100 \rho_{e q}\left(1+7.5 \frac{f_{\text {Ftuk }}}{f_{c t k}}\right) f_{c k}\right]^{1 / 3}+0.15 \sigma_{c p}\right\} b_{w} d_{e q}
$$

where 


$$
\rho_{e q}=\frac{A_{l}}{b_{w} d_{l}}+\frac{A_{p}}{b_{w} d_{p}}
$$

is the flexural reinforcement ratio in the general case of a R/SFRC beam with passive and prestressed reinforcements, being $A_{l}$ and $d_{l}$, and $A_{p}$ and $d_{p}$ their corresponding cross sectional area and internal arm, and $b_{w}$ the width of the web of the section, while

$$
d_{e q}=\frac{d_{l} A_{l}+d_{p} A_{p}}{A_{l}+A_{p}}
$$

is the equivalent internal arm of the flexural reinforcement.

In Eq. (2a) $f_{F t u k}$ is the post-cracking residual tensile strength obtained from either a direct tensile test of by inverse analysis on prism bending test data; $f_{c t k}$ is the characteristic tensile strength of the FRC; $\gamma_{c}$ is a partial safety factor $\left(\gamma_{c}=1.5\right), \sigma_{c p}=N_{s d} / A_{c}<0.2 f_{c k} / \gamma_{c}$ is the average stress acting on the concrete cross section, $A_{c}$, for an axial force, $N_{s d}$, due to loading or prestressing actions ( $N_{s d}>0$ for compression); and $k$ is a factor that takes into account the size effect and given by:

$$
k=1+\sqrt{200 / d_{e q}} \leq 2.0 \quad\left(d_{e q} \text { in } \mathrm{mm}\right)
$$

The characteristic post-cracking residual tensile strength $\left(f_{F t u k}\right)$ of the SFRC for shear is determined at a crack opening displacement (COD) of $w_{u}=1.5 \mathrm{~mm}$, and is given by:

$$
f_{\text {Ftuk }}=0.45 f_{R 1 k}-0.6\left(0.65 f_{R 1 k}-0.5 \cdot f_{R 3 k}\right) \geq 0
$$

where $f_{R 1 k}$ and $f_{R 3 k}$ are flexural strengths determined in accordance with MC2010. In the database that will be introduced in Section 4 for the assessment of the predictive performance of the MC2010 approaches, the $f_{R i}$ values of the SFRC of some beams are not available. For these cases, the $f_{R 1 k}$ and $f_{R 3 k}$ are estimated from the relationship proposed by Moraes-Neto [33] and Moraes-Neto et al. [34]:

$$
f_{R i}=k_{1}\left(V_{f} l_{f} / d_{f}\right)^{k_{2}} \quad \ldots i=1,2,3,4
$$


where $k_{1}=10.5,9.2,8.0 .7 .0$ and $k_{2}=0.80,0.75,0.70,0.65$ for $f_{R 1}, f_{R 2}, f_{R 3}$ and $f_{R 4}$, respectively (the values for $f_{R 2}$ are interpolated from those for $f_{R 1}$ and $f_{R 3}$ ). Although the authors recognize the $f_{R i}$ values cannot only be dependent on the $V_{f}, l_{f}$ and $d_{f}$ fibre characteristics, later it will be verified they can be predicted with reasonable accuracy from Eq. (5) in the context of the present study.

The equation for determining the contribution of the transverse bar reinforcement $\left(V_{R d, s}\right)$ is not provided since the present database do not include any R/SFRC beam with this reinforcement, but it can be consulted in the MC2010.

The design shear resistance cannot be greater than the crushing capacity of concrete in the web:

$$
V_{R d, \max }=k_{c} \cdot \frac{f_{c k}}{\gamma_{c}} \cdot b_{w} \cdot z \cdot \frac{\cot \theta+\cot \alpha}{1+\cot ^{2} \theta}
$$

where $z=0.9 d_{e q}$ is the effective shear depth, $\theta$ is the inclination of the CDC, $k_{c}=k_{\varepsilon} \eta_{f c}$, $k_{\varepsilon}=0.55$ and:

$$
\eta_{f_{c}}=\left(30 / f_{c k}\right)^{1 / 3} \leq 1.0 \quad\left(f_{c k} \text { in } \mathrm{MPa}\right)
$$

\subsection{Approach based on the modified compression field theory (MCFT)}

The second approach proposed in the MC2010 for the determination of the shear capacity of R/SFRC beams was developed from the MCFT [27], and is herein denoted as MC2010_MCFT. By this approach the shear capacity of an R/SFRC beam is calculated from Eq. (1) with:

$$
V_{R d, F}=\frac{1}{\gamma_{F}}\left(k_{v} \sqrt{f_{c k}}+k_{f} f_{F t u k}(w) \cot \theta\right) z b_{w} \quad \ldots \text { with } \sqrt{f_{c k}} \leq 8 M P a
$$

where $k_{f}=0.8$ is factor to account for fibre dispersion, $f_{\text {Ftuk }}$ is the post-cracking residual tensile strength obtained from a direct tensile test, and $k_{v}$ is a size effect parameter.

The size/strain effect parameter is related to the longitudinal strain determined at the mid-depth of the section $\left(\varepsilon_{x}\right)$ and to the size of the largest aggregate particles $\left(d_{g}\right)$ by: 


$$
\begin{aligned}
& k_{v}=\left\{\begin{array}{c}
\frac{0.4}{1+1500 \varepsilon_{x}} \frac{1300}{1000+z k_{d g}} \quad \ldots \text { for } \rho_{w}<0.08 \sqrt{f_{c k}} / f_{l y k} \\
\frac{0.4}{1+1500 \varepsilon_{x}} \quad \ldots \text { for } \rho_{w} \geq 0.08 \sqrt{f_{c k}} / f_{l y k}
\end{array}\right. \\
& k_{d g}=\left\{\begin{array}{l}
\frac{32}{16+d_{g}} \geq 0.75 \ldots \text { for normal-weight concrete with } f_{c k} \leq 70 \mathrm{MPa} \\
2.0 \quad \ldots \text { for } f_{c k}>70 \mathrm{MPa} \text { and for light-weight concrete }
\end{array}\right.
\end{aligned}
$$

where $f_{l y k}$ is the characteristic value of the yield strength of the main longitudinal bars, and $d_{g}$ is in $\mathrm{mm}$.

The mid-depth longitudinal strain is calculated for reinforced concrete (RC) and prestressed concrete (PC) beams from:

$$
\varepsilon_{x}= \begin{cases}\frac{1}{2 E_{l} A_{l}}\left(\frac{M_{E d}}{z}+\frac{V_{E d} \cot \theta}{2}+N_{E d}\left(\frac{1}{2}-\frac{\Delta e}{z}\right)\right) & \ldots \text { for RC beams } \\ \frac{\left(\frac{M_{E d}}{z}+\frac{V_{E d} \cot \theta}{2}+N_{E d}\left(\frac{1}{2}-\frac{\Delta e}{z}\right)\right)}{2\left(\frac{z_{l}}{z} E_{l} A_{l}+\frac{z_{p}}{z} E_{p} A_{p}\right)} & \ldots \text { for PC beams }\end{cases}
$$

within the limits $0 \leq \varepsilon_{x} \leq 0.003$.

In Eq. (10), $M_{E d}, V_{E d}$ and $N_{E d}$ are the design values of the bending moment, shear and axial forces acting on the cross section, respectively. The bending moment and shear force are taken as positive; the axial force is positive for tension and negative for compression. The eccentricity of the beam axis with respect to section mid-depth $(\Delta e)$, shown in Fig 1, is a positive value when positioned above the centre of gravity of the cross section. For R/SFRC hybrid flexurally reinforced beams, with passive (subscript "l") and prestressed (subscript " $p$ ")reinforcements, the effective shear depth, $z$, is evaluated from:

$$
z=\frac{z_{l}^{2} A_{l}+z_{p}^{2} A_{p}}{z_{l} A_{l}+z_{p} A_{p}}
$$


In Eqs. (6) to (8), the angle of the compressive stress field, $\theta$, for SFRC is:

$$
\theta=29^{\circ}+7000 \varepsilon_{x} \leq 45^{\circ}
$$

The post-cracking residual tensile stress at ultimate $\left(f_{F t u k}\right)$ in Eq. $(8)$ is determined using a direct tensile test for a crack opening of:

$$
w_{u}=0.2+1000 \varepsilon_{x} \geq 0.125 \mathrm{~mm}
$$

Based on an inverse analysis carried out by Amin et al. [35] by using experimental results from bending tests, the following equation was derived for the evaluation of the post-cracking residual tensile strength for a given $\mathrm{COD}, w$ :

$$
\begin{aligned}
& f_{F t u k}(w)=k_{G} \min \left(0.4 f_{R 2}+1.2\left(f_{R 4}-f_{R 2}\right) \xi(w), f_{c t k, \min }\right) \\
& \xi(w)=\alpha w-0.25
\end{aligned}
$$

which has since been validated for use with the MC2010_MCFT model [29]. The $\alpha$ parameter in Eq. (14b) is equal to 5/12 For the prism bending test configuration of EN 14651 [36] and RILEM TC 162-TDF Guidelines [37], equal to 1/3 for the configuration of ASTM C1609, and equal to $43 / 84$ for the Italian Guideline [38]. In Eq. (14a) $f_{c t k \text {, min }}$ is the minimum characteristic tensile strength of the matrix (and may be taken as $f_{c t k, \min }=0.7\left(0.3 f_{c k}{ }^{2 / 3}\right)$ ), and $k_{G}$ is a factor that takes into account fibre alignment due to casting bias and wall influences that occur in the prism bending test and equals 0.7 for the ASTM 1609 test and 0.6 for the EN 14651, RILEM TC 162-TDF and UNI 11039 tests. The $f_{F t u k}\left(w=w_{u}\right)$ is evaluated for the crack opening at shear failure conditions ( $w=w_{u}$ ), obtained according to Eq. (13).

For the MCFT approach, web crushing $\left(V_{R d, \max }\right)$ is determined by Eq. (6) with:

$$
\begin{aligned}
& k_{\varepsilon}=\frac{1}{1.2+55 \varepsilon_{1}} \leq 0.65 \\
& \varepsilon_{1}=\varepsilon_{x}+\left(\varepsilon_{x}+0.002\right) \cot ^{2} \theta
\end{aligned}
$$




\section{Integrated Shear Model for Design of SFC Beams}

\subsection{Introduction}

In this section a new model is developed for the evaluation of the shear capacity of R/SFRC beams. While the model is proposed only for SFRC members, as testing has almost exclusively been undertaken with steel fibres, it is prepared for being extended to the general case of R/FRC beams.

The tensile strength provided by the fibre pull-out resistance is determined for a crack width $w_{u}$. As for the MC010_MCFT approach, the concrete and fibre reinforcement contribution for the shear capacity of an R/SFRC beam is determined from:

$$
V_{R d, F}=k_{f}\left(V_{R d, c}+V_{R d, f}\right)
$$

where:

$$
\begin{aligned}
V_{R d, c} & =\frac{k_{p} k_{v}}{\gamma_{F}} \sqrt{f_{c k}} z b_{w} \text { with } \sqrt{f_{c k}} \leq 8 M P a \\
V_{R d, f} & =\frac{F_{f u k}\left[w_{u v}\left(w_{u}\right)\right]}{\gamma_{F}}
\end{aligned}
$$

where $F_{f u k}\left[w_{u v}\left(w_{u}\right)\right]$ is evaluated considering the fibre orientation profile (FOP), the fibre pull-out constitutive law (FPCL) representative of each domain adopted for the FOP, and the corresponding number of fibres crossing the CDC. The $\left[w_{u v}\left(w_{u}\right)\right]$ means that $F_{f u k}$ is evaluated for the variable $w_{u v}$ (vertical movement of the two faces composing the CDC) that depends of $w_{u}$ (crack opening orthogonal to the CDC plane at shear failure conditions) as will be demonstrated in Section 3.3.

In Eq. (16b) $k_{p}$ is a parameter that simulates the favourable effect of prestress in terms of extra shear capacity, adapted from the proposal of [20]:

$$
k_{p}=\sqrt{1+2.0 \frac{\sigma_{c p}}{f_{c t k}}}
$$


In Eqs. (16a) $k_{f}$ is a parameter that simulates the contribution of the flanges of T-and I-section beams to the shear capacity of R/SFRC beams. This favourable effect was already verified elsewhere [37, 39], which is not specific of FRC, being only a consequence of the extra shear fracture surface at the web-flange connexion. Since fibres are also crossing this surface, the $k_{f}$ factor should affect $V_{R d, F}$. The Eq. (18) for the determination of $k_{f}$ is an extension of the equation proposed by Baghi and Barros [39] for T cross-section RC beams in order to also simulate the favourable contribution provided by I cross-section RC beams.

$$
\begin{aligned}
& k_{f}=1+\frac{n}{s}\left(\frac{h_{c, e q}}{b_{w}}\right)\left(\frac{h_{c, e q}}{d_{e q}}\right) \leq 1.5 \\
& n=\frac{b_{c, e q}-b_{w}}{h_{c, e q}} \leq 3 \wedge n \leq 3 \frac{b_{w}}{h_{c, e q}} \\
& s= \begin{cases}2, & \text { T-section } \\
6, & \text { I-section }\end{cases}
\end{aligned}
$$

where $b_{c, e q}$ and $h_{c, e q}$ are the equivalent of the width and height of the flange (Fig. 2):

$$
\begin{aligned}
& b_{c, e q}=\frac{b_{c} A_{c 1}+\left(b_{c}+b_{w}\right) / 2 A_{c 2}}{A_{c 1}+A_{c 2}} \\
& h_{c, e q}=\frac{h_{c 1} A_{c 1}+h_{c 2} A_{c 2}}{A_{c 1}+A_{c 2}}
\end{aligned}
$$

The model, named as Integrated Shear Model (ISM), is based on the following strategy: (i) evaluation of fibre distribution profile (FOP) according to the approach proposed by Oliveira [40]; (ii) determination of the resisting stress assured by fibres bridging the CDC, $f$ fuk $(w)$, by considering the fibre pull-out resistance according to the recommendations of $\mathrm{Ng}$ et al. [41, 42]; and (iii) evaluation of crack width at mid depth of the CDC, at shear failure conditions, $w_{u}$, by using the MCFT [43]. The integration of these three parts is described in the following sections.

\subsection{Fibre orientation profile}

The contribution of fibre reinforcement crossing the CDC can be determined by: 


$$
F_{f u k}\left[w_{u v}\left(w_{u}\right)\right]=\sum_{i=1}^{n \Delta \varphi} P_{f u k, \varphi_{i}}\left[w_{u v}\left(w_{u}\right)\right]
$$

where $n \Delta \varphi$ is the number of intervals in the fibre orientation range [0-90 $]$ adopted for the evaluation of the fibre orientation profile, and $P_{f u k, \varphi_{i}}\left(w_{u}\right)$ is the force supported by the percentage of fibres with an inclination $\varphi_{i}$, obtained for a crack opening representative of the shear failure condition, $w_{u}$ (Fig. 3), where $\varphi_{i}$ is the angle between the direction of the fibres representative of the $i^{\text {th }}$ fibre orientation interval and the orthogonal to the crack plane (Fig. 3bf).

Fig. 3 illustrates conceptually the proposed approach. The figure shows the domain of fibre orientation decomposed in four equal intervals of $22.5^{\circ}\left(n \Delta \varphi=4 ; \Delta \varphi=22.5^{\circ}\right)$. The $P_{f u k, \varphi_{i}}\left(w_{u}\right)$ is evaluated in the middle of each interval by considering the number of fibres with orientation in this interval, therefore Eq. (19) becomes:

$$
\begin{aligned}
F_{f u k}\left[w_{u v}\left(w_{u}\right)\right] & =P_{f u k, 11.25^{\circ}}\left[w_{u v}\left(w_{u}\right)\right]+P_{f u k, 33.75^{\circ}}\left[w_{u v}\left(w_{u}\right)\right] \\
& +P_{f u k, 56.25^{\circ}}\left[w_{u v}\left(w_{u}\right)\right]+P_{f u k, 78.75^{\circ}}\left[w_{u v}\left(w_{u}\right)\right]
\end{aligned}
$$

where $P_{f u k, \varphi_{i}}\left[w_{u v}\left(w_{u}\right)\right]\left(\varphi_{i}=11.25^{\circ}, 33.75^{\circ}, 56.25^{\circ}\right.$ and $\left.78.75^{\circ}\right)$ are the forces supported by the percentage of fibres within inclination intervals $\left[0-22.5^{\circ}\left[,\left[22.5^{\circ}-45^{\circ}\left[,\left[45^{\circ}-67.5^{\circ}[\right.\right.\right.\right.\right.$ and $\left[67.5^{\circ}-90^{\circ}\right]$, respectively, at $w_{u}$.

The force $P_{f u k, \varphi_{i}}\left[w_{u v}\left(w_{u}\right)\right]$ is determined from:

$$
P_{f u k, \varphi_{i}}\left[w_{u v}\left(w_{u}\right)\right]=P_{\varphi_{i}}^{F P L}\left[w_{u v}\left(w_{u}\right)\right] N_{f, \varphi_{i}}
$$

where $P_{\varphi_{i}}^{F P C L}\left[w_{u v}\left(w_{u}\right)\right]$ is the resisting pull-out force for the crack opening of $w_{u}$ for a fibre at an inclination $\varphi_{i}$, described in the following section, and $N_{f, \varphi_{i}}$ is the number of fibres crossing the CDC within the range of orientations $\varphi_{i} \pm \Delta \varphi_{i} / 2$ :

$$
\begin{aligned}
& N_{f, \varphi_{i}}=C\left(\varphi_{i}\right) N_{f} \\
& N_{f}=\frac{A_{s e c}}{A_{f}} V_{f} \eta_{\varphi}
\end{aligned}
$$


where $A_{f}, V_{f}$ and $\eta_{\varphi}$ are the cross sectional area of a fibre, the fibre volume percentage, and the fibre orientation factor, respectively.

In Eq. (22b) $A_{\text {sec }}$ is the area of CDC (Fig. 3a):

$$
A_{s e c}=\frac{z}{\sin \theta} b_{w}
$$

where $\theta$ is the inclination of the CDC.

In Fig. $3 \mathrm{c}$ to $3 \mathrm{f}$ the "equivalent" fibre crossing the CDC represents the total number of fibres bridging the $\mathrm{CDC}$ for the corresponding range orientation. As will be explained later, the part of the fibres bridging the two faces of the shear failure crack is almost aligned with the shear force applied to the beam.

In Eq. (22a), $C\left(\varphi_{i}\right)$ is the ratio of number of fibres crossing the CDC that lie in the range $\varphi_{i} \pm \Delta \varphi_{i} / 2$ to the total number of fibres crossing the crack, which evaluation approach is described in detail elsewhere [40], therefore in the present work only the relevant concepts and equations are presented, namely:

$$
C\left(\varphi_{i}\right)=f\left(\varphi_{i}\right) F_{R E}\left(\eta_{\varphi}\right)
$$

where $f\left(\varphi_{i}\right)$ is the frequency of fibres within $\varphi_{i} \pm \Delta \varphi_{i} / 2$ and $F_{R E}\left(\eta_{\varphi}\right)$ accounts for the error that results from adopting discrete ranges of $\Delta \varphi_{i}$, compared with a continuous distribution function:

$$
F_{R E}\left(\eta_{\varphi}\right)=\left\{\begin{array}{cc}
1.29-0.38 \eta_{\varphi} & \text { for } \eta_{\varphi}<0.75 \\
1 & \text { for } \eta_{\varphi} \geq 0.75
\end{array}\right.
$$

For the evaluation of the fibre orientation factor, $\eta_{\varphi}$, an enhanced strategy of the approach proposed by Krenchel [44] is adopted in order to take into account the fibre orientation during the cracking process up to shear failure stage, as well as the wall effect due to the element boundaries on fibre orientation. In consequence, the $\eta_{\varphi}, C\left(\varphi_{i}\right)$ and $N_{f, \varphi_{i}}$ entities become 
interdependent and their evaluation are obtained by performing the following iterative procedure:

Step 1: Assuming the wall effect is limited to a distance $l_{f} / 2$ of the boundaries, the cross section is decomposed in three zones (Fig. 4). In zone 1 fibres can freely rotate in any direction and a 3D fibre orientation is assumed; in zone 2 a 2D fibre orientation is considered; and in zone 3, with two boundaries. The fibre orientation factor for this type of cross section is determined by:

$$
\eta_{\varphi}=\frac{\eta_{\varphi, 1}\left(b_{w}-l_{f}\right)\left(z / \sin \theta-l_{f}\right)+\eta_{\varphi, 2} l_{f}\left[\left(b_{w}-l_{f}\right)+\left(z / \sin \theta-l_{f}\right)\right]+\eta_{\varphi, 3} l_{f}^{2}}{b_{w} z / \sin \theta}
$$

For the initial trial $\left(\eta_{\varphi, \text { Initial_Trial }}\right)$ the values of $\eta_{\varphi, i}(i=1,2,3)$ proposed by Krenchel are adopted, namely, $\eta_{\varphi, 1}=\eta_{\varphi, 1 K}=0.5, \eta_{\varphi, 2}=\eta_{\varphi, 2 K}=2 / \pi, \eta_{\varphi, 3}=\eta_{\varphi, 3 K}=0.84$, but these values are updated taking into account the estimated fibre orientation in the initial and final cracking stages.

Step 2: Evaluation of the factor accounting for the range error, $F_{R E}(\varphi)$, for the $\eta_{\varphi}$ obtained in step 1, according to Eq. (26).

Step 3: Evaluate the average orientation angle, $\varphi_{m}$, and the corresponding standard deviation, $\sigma\left(\varphi_{m}\right)$ (see Fig. 5), according to the approach of [40]:

$$
\begin{gathered}
\varphi_{m}=\arccos \left(\eta_{\varphi}\right) 180 / \pi \\
\sigma\left(\varphi_{m}\right)=90 \eta_{\varphi}\left(1-\eta_{\varphi}\right)
\end{gathered}
$$

Step 4: Decomposition of the full domain of fibre orientations $\left[0-90^{\circ}\right]$ in selected intervals $(\Delta \varphi)$, and evaluation of the relative frequency of each interval, $f\left(\bar{\varphi}_{i}\right)$, at the sampling fibre orientations. For each interval $\Delta \varphi$ (Fig. 5):

- Calculate $\bar{\varphi}_{i}=\left(\varphi_{i}+\varphi_{i-1}\right) / 2$

- Determine $f\left(\bar{\varphi}_{i}\right)=F\left(\varphi_{i}, \varphi_{m}, \sigma\left(\varphi_{m}\right)\right)-F\left(\varphi_{i-1}, \varphi_{m}, \sigma\left(\varphi_{m}\right)\right)$, where $F\left(\varphi, \varphi_{m}, \sigma\left(\varphi_{m}\right)\right)$ is the cumulative distribution of the standardized Gaussian law at $\varphi$.

- Evaluate $C\left(\bar{\varphi}_{i}\right)$ according to Eq. (24) and $N_{f, \bar{\varphi}_{i}}$ according to Eq. (22). 
Since the ISM was implemented in Excel VBA, the $f\left(\varphi_{i}\right)$ was evaluated by using the NORM.DIST function that returns the normal distribution for the specified average $\left(\varphi_{m}\right)$ and standard deviation $\left(\sigma\left(\varphi_{m}\right)\right)$ values.

Step 5: Estimate the fibre orientation factor at the initial cracking stage by considering the fibre orientation and the number of fibres at each interval $\left(\bar{\varphi}_{i}, N_{f, \bar{\varphi}_{i}}\right)$ at this stage (since $N_{f, \bar{\varphi}_{i}}$ and $N_{f}$ are dependent of $\eta_{\varphi}$, Eq. (22), the process of its evaluation is iterative):

$$
\eta_{\varphi, i c s}=\frac{\sum_{i=1}^{n \Delta \varphi} N_{f, \bar{\varphi}_{i}} \cos \left|\bar{\varphi}_{i}\right|}{N_{f}}
$$

Step 6: Estimate the fibre orientation factor at shear failure conditions (fibres are aligned vertically, see Figure 6):

$$
\eta_{\varphi, f c s}=\cos \theta_{u}
$$

Step 7: Assume the average of previous values as a reliable estimative of fibre orientation factor:

$$
\eta_{\varphi, c s}=\frac{\eta_{\varphi, i c s}+\eta_{\varphi, f c s}}{2}
$$

Step 8: Re-evaluate $\eta_{\varphi}$ according to Eq. (26), but now updating the $\eta_{\varphi, i}(i=1,2,3)$ proposed by [44] in order to simulate the fibre orientation according to the two previous scenarios:

$$
\begin{aligned}
& \eta_{\varphi, 1}=\eta_{\varphi, c s} \\
& \eta_{\varphi, 2}=\eta_{\varphi, 2 K} \frac{\eta_{\varphi, c s}}{\eta_{\varphi, 1 K}} \\
& \eta_{\varphi, 3}=\eta_{\varphi, 3 K} \frac{\eta_{\varphi, c s}}{\eta_{\varphi, 1 K}}
\end{aligned}
$$

A maximum limiting value of 0.85 is adopted for the $\eta_{\varphi, i}$. This iterative procedure is assumed converged when $\left|\eta_{\varphi, c s, \text { actual }}-\eta_{\varphi, c s, \text { previous }}\right| / \eta_{\varphi, \text { Initial__Trial }}<0.001$. 


\subsection{Fibre pullout constitutive law}

The evaluation of the pull-out force $N_{f, \bar{\varphi}_{i}}$ for fibres orientated at $\bar{\varphi}_{i}$, for a crack opening displacement (COD) $w, P_{\bar{\varphi}_{i}}^{F P C L}(w)$, is obtained according to the unified variable engagement model (UVEM) proposed by [41, 42], while for the evaluation of crack width at shear failure $\left(w_{u}\right)$ at the mid-depth $(z / 2)$, the MCFT is used, as described in the following section.

According to [45], a fibre at $N_{f, \bar{\varphi}_{i}}$, of orientation $\bar{\varphi}_{i}$, is activated when the COD (vertical direction) equals the crack width required for engagement:

$$
w_{e v, i}=\frac{1}{3.5} d_{f} \tan ^{3}\left(\frac{\gamma_{u, i}}{\gamma_{u}^{\max }} \frac{\pi}{2}\right)
$$

where $\gamma_{u, i}$ is the angle between the direction of loading $(F)$ and fibre orientation, as shown in

Fig. 6, while $\gamma_{u}^{\max }$ is its maximum value, both cases at shear failure conditions (represented by the subscript $u$ ). In this figure $\bar{\varphi}_{i}$ represents the fibre orientation of the $i^{t h}$ interval (towards the normal to the CDC plane, taken as positive in the clockwise direction), $\phi$ is the orientation of loading towards the normal to the CDC plane (due to the almost vertical movement of the crack opening process of the CDC, Fig. 6, it is assumed $\phi=\theta$ ), and $w$ and $s$ are the crack opening and sliding displacements, respectively.

For a pull-out failure mechanism, when a crack opens, on one side the fibre remains embedded in the matrix and on the other it slips. The average bonded length of fibre crossing the failure plane $\left(L_{b f, o}\right)$, on the short embedment side, is $l_{f} / 4$.

From the geometry described in Fig. 6:

$$
\begin{aligned}
& \gamma_{u, i}=\left|\bar{\varphi}_{i}-\phi_{u}\right| \text { for } 0 \leq \gamma_{u, i} \leq \pi \\
& \gamma_{u}^{\max }=\left|\phi_{u}\right|+\pi / 2 \text { for } \pi / 2 \leq \gamma_{u}^{\max } \leq \pi
\end{aligned}
$$

According to the UVEM, $P_{\bar{\varphi}_{i}}^{F P C L}\left(w_{u}\right)$ is given by:

$$
P_{\bar{\varphi}_{i}}^{F P C L}\left[w_{u v}\left(w_{u}\right)\right]=k_{u, i} \pi d_{f} \tau_{b u, i} L_{b f, o}
$$

where 


$$
k_{u, i}=\left\{\begin{array}{cc}
0 . \text { for }\left\{\begin{array}{c}
w_{u v}<w_{e v, i} \\
w_{u v} \geq L_{b f, o} \\
L_{b f, o}-w_{u v} \geq L_{c r u, i}
\end{array}\right. \\
\frac{2\left(L_{b f, o}-w_{u v}\right)}{l_{f}} & \ldots \text { for } w_{e v, i} \leq w_{u v}<L_{b f, o}
\end{array}\right.
$$

with (Fig. 6):

$$
w_{u v}=\frac{w_{u}}{\cos \left(\phi_{u}\right)}
$$

The fibre embedment length $L_{c r u, i}$ is a critical length beyond which the force in the fibre, due to bond, is such at the fibre fractures, rather than slips, and is given by [45]:

$$
L_{c r u, i}=\frac{d_{f}}{2} \frac{\bar{\sigma}_{f u}}{\tau_{b u, i}}
$$

In this equation $\tau_{b u, i}$ is the average fibre bond strength and includes the relevant fibre reinforcement mechanisms (e.g. hooked ends, if provided) and the snubbing effect [46-49], and $\bar{\sigma}_{f u}$ is the effective tensile strength of the fibre:

$$
\bar{\sigma}_{f u}=\sigma_{f u} \frac{\pi}{2 \gamma_{u}^{\max }}
$$

where $\sigma_{f u}$ is the uniaxial tensile strength of the fibre.

From test results on hooked end and straight steel fibres by [45-49], $\mathrm{Ng}$ et al. [42] proposed:

$$
\tau_{b u, i}=k_{b} \sqrt{f_{c m}}+f\left[1-\cos \left(\frac{\gamma_{u, i}}{2}\right)\right]
$$

where $f_{c m}$ is the average value of the concrete compressive strength, $f=4.5 \mathrm{MPa}$ is the maximum frictional resistance of the fibre due to the snubbing effect, and $k_{b}$ is given in Table 1 . 


\subsection{Coupling the modified compression field theory with the FOP and FPCL}

To evaluate the crack opening at the half of the effective shear depth $(z / 2)$ at shear failure stage, $w_{u}$, (a value normal to the CDC plane), the MCFT is used. The MCFT is based on the following iterative procedure:

1) Assume an initial value for $\varepsilon_{x}$ (denoted as $\varepsilon_{x, i}$ ).

2) Calculate $k_{v}$ by Eq. (9), with:

$$
f_{l y k}=\frac{E_{l} \varepsilon_{l y k} A_{l}+\left(E_{p} \varepsilon_{p y k}-f_{p o}\right) A_{p}}{A_{l}+A_{p}}
$$

where for the case of beams reinforced with passive and prestressed longitudinal reinforcements, $\varepsilon_{l y k}$ and $\varepsilon_{p y k}$ are the characteristic value of the yield strain of passive and prestressed longitudinal reinforcement, respectively, and $f_{p o}$ is the applied prestress.

3) Evaluation of the angle of the compressive stress field, $\theta$, according to an updated version of the Eq. (12) in order to take into account the beneficial effects of fibre reinforcement and the compressive axial load in the prestressed R/SFRC beams, as proposed by Soetens [20]:

$$
\theta=\operatorname{Min}\left(\left\{\begin{array}{l}
29^{\circ}+7000 \varepsilon_{x} \leq 45^{\circ} \text { for } V_{f}>0 \\
20^{\circ}+10000 \varepsilon_{x} \leq 75^{\circ} \text { for } V_{f}=0
\end{array}, \operatorname{arctg}\left(1+4 \frac{\sigma_{c p}}{f_{c k}}\right)\right.\right.
$$

The maximum limit of $75^{\circ}$ is according to the recommendation from [43].

4) Calculate of the crack width at $z / 2$, orthogonal to the CDC, $w_{u}$ :

$$
w_{u}=\left(0.2+1000 \varepsilon_{x}\right)\left(\frac{1000+z k_{d g}}{1300}\right) \geq 0.125 \mathrm{~mm}
$$

and its component in the vertical direction, $w_{u v}$ (direction of crack opening at shear failure condition of this type of beams, Fig. 6), according to Eq. (36c).

5) Calculate $k_{p}$ from Eq. (17).

6) Calculate $V_{R d, c}$ from Eq. (16b). 
7) Calculate $V_{R d, f}$ from Eq. (16c), with $F_{f u k}\left(w_{u}\right)$ obtained by Eq. (19) in combination with the FOP and FPCL models set out in Sections 3.2 and 3.3 of this paper.

8) Calculate $k_{f}$ according to Eq. (18).

9) Calculate $V_{R d, F}$ according to Eq. (16a) (and adding the $V_{R d, s}$ component according to the MC2010 if beam includes conventional shear ligatures).

10) Calculate $V_{R d}$ according to Eq. (1). Check $V_{R d}$ does not exceed web crushing limit, $V_{R d, \max }$, calculated from Eqs. (7) and (15).

11) Determine the new estimate of the mid-depth longitudinal strain $\left(\varepsilon_{x}\right)$ for current iteration, $\varepsilon_{x, i+1}$, according to Eq. (10), by adopting: $V_{E d}=V_{R d}, M_{E d}=V_{R d}\left(a-d_{e q}\right)$ and the applied prestressed force for $N_{E d}$.

12) If $\left|\left(\varepsilon_{x, i+1}-\varepsilon_{x, i}\right)\right| / \varepsilon_{l y k} \leq \varepsilon_{t o l}$, the solution is converged, else return to step 2 with $\varepsilon_{x, i}$ $=\varepsilon_{x, i+1} \cdot\left(\varepsilon_{t o l}=1 \times 10^{-6}\right)$ and repeat until converged.

At the conclusion of the iterative procedure the shear strength on the member $V_{R d}$ is determined, together with each of the sub-components $V_{R d, F}$ (consisting of $V_{R d, c}$ and $V_{R d, f}$ ) and $V_{R d, s}$. The capacity of the member is determined as the lesser of its shear and flexural strength.

To demonstrate the procedure, the developed ISM is applied to the NSC3-FRC1 rectangular cross shape beam tested by Minelli et al. [6], which presents the following characteristics:

i) Beam's geometry: $b_{w}=200 \mathrm{~mm}, h=480 \mathrm{~mm}, a=1090 \mathrm{~mm}$;

ii) Concrete: $f_{c m}$ (cylinders) $=38.6 \mathrm{MPa}, d_{g}=20 \mathrm{~mm}$;

iii) Fibres: HS, $V_{f}=0.38, l_{f}=30 \mathrm{~mm}, d_{f}=0.6 \mathrm{~mm}, \sigma_{f u}=1100 \mathrm{MPa}$, $f_{R 1 m}=3.34 \mathrm{MPa}, f_{R 3 m}=2.73 \mathrm{MPa}$;

iv) Longitudinal reinforcement: $A_{l}=905 \mathrm{~mm} 2, d_{l}=435 \mathrm{~mm}, \rho_{l}=1 \%, E_{l}=200 \mathrm{GPa}$, $\varepsilon_{l y}=2.56 \%$.

The results of the MCFT module applied to specimen NSC3-FRC1 are as follows: $\varepsilon_{x}=858 \mu \varepsilon$, $\theta=35^{\circ}, \quad w_{u}=1.10 \mathrm{~mm}, \quad w_{u v}=1.34 \mathrm{~mm}, \quad \gamma_{u}^{\max }=125^{\circ}, \quad k_{v}=0.17, \quad V_{R d, c}=82.08 \mathrm{kN}$, 
$V_{R d, f}=F_{f u k}=47.90 \mathrm{kN}, k_{f}=1, V_{R d, F}=130 \mathrm{kN}, V_{R d, \max }=832.8 \mathrm{kN}$. For this beam the model calculates a shear capacity of $V_{R d}=130 \mathrm{kN}$, while a value $138.5 \mathrm{kN}$ was registered experimentally, therefore $\lambda=V_{\text {test }} / V_{\text {model }}=1.07$.

The main ISM outputs for the NSC3-FRC1 beam are plotted in Fig. 7 and included in Table 2. Fig. 7a shows the number of fibres for the nine intervals considered, while Fig. $7 \mathrm{~b}$ reveals that $\gamma_{u, i}$ increases with $\left|\bar{\varphi}_{i}\right|$, being null for $\bar{\varphi}_{i}=\phi_{u}\left(=\theta_{u}\right) \approx 35^{\circ}$, when fibres are aligned vertically (Fig. 6). Due to the profile of $\gamma_{u, i}$, and since the engagement crack width, $w_{e v, i}$, increases with $\gamma_{u, i}$ (Eq. (33)), the fibres oriented more closely to the direction of crack opening are firstly activated (smaller values of $w_{e v, i}$ ). However, since the snubbing fibre reinforcement mechanism increases with $\gamma_{u, i}$ (Eq. (39)), and considering the $\gamma_{u, i}$ has decreased with the decrease of the $\left|\bar{\varphi}_{i}\right|$ (Fig. 7b), the fibre bond strength, $\tau_{b u, i}$, has decreased with the decrease of $\left|\bar{\varphi}_{i}\right|$, as shown in Fig. 7c. The opposite is observed for $L_{c r u, i}$, Fig. 7d, which increases with the decrease of $\left|\bar{\varphi}_{i}\right|$ ), since $L_{c r u, i}$ decreases with the increase of $\tau_{b u, i}$ and the decrease of $\bar{\sigma}_{f u}$ (Eq. (37)), which simulates the tendency to tensile rupture of the fibre when the bond strength increases, and/or the CDC orientation becomes close to $\pi / 2\left(\phi_{u}=\theta_{u}=>\gamma_{u}^{\max }=\pi\right.$, Eqs. (35) and (38)). Due to the relatively large values $w_{e, i}$ for the fibres oriented at $\bar{\varphi}_{i}$ between $-85^{\circ}$ and $-55^{\circ}$, these fibres do not contribute for the post-tensile capacity provided by fibres bridging the CDC (Fig. 7e), but for the remaining fibre orientation intervals the capacity ensured by the fibre pull-out mechanism $\left(P_{\bar{\varphi}_{i}}^{F P C L}\left(w_{u}\right)\right)$ has a smooth increase with $\left|\bar{\varphi}_{i}\right|$.

Finally, Fig. 7f represents the product of the $P_{\bar{\varphi}_{i}}^{F P C L}\left(w_{u}\right)$ (results from Fig. 7e) with the number of fibres for each of the intervals of fibre orientation profile considered, $N_{f, \bar{\varphi}_{i}}$ (Fig. 7a). It is verified that, apart from the intervals $\bar{\varphi}_{i}$ from $-85^{\circ}$ to $-55^{\circ}$ where $P_{\bar{\varphi}_{i}}^{F P C L}\left(w_{u}\right)=0$, the component $P_{\bar{\varphi}_{i}}^{F P C L}\left(w_{u}\right) \cdot N_{f, \bar{\varphi}_{i}}$ is mainly governed by the distribution of the number of fibres (Fig. 7a), as $P_{\bar{\varphi}_{i}}^{F P C L}\left(w_{u}\right)$ has not changed significantly on the fibre orientation profile (Fig. 7e). 


\section{Model Assessment and Validation}

To evaluate performance of the model the database developed for Foster et al. [29] was expanded; additional tests included prestressed concrete members and beams reinforced with crimped (C), and flat end (FH) fibres, as well as high-strength (HS) fibres. A large database in this regards was also recently published in [30], which includes many of the beams considered in this work for the assessment of the predictive performance of the ISM. After having eliminated the tests of R/SFRC beams of the flexural capacity (evaluated according the recommendation of MC2010) less than the maximum actuating bending at the registered experimental ultimate shear load, i.e. yield initiation of the flexural reinforcement has already occurred, the database was composed of $122 \mathrm{R} / \mathrm{SFRC}$ beams from 21 experimental research programs. Thirty seven beams have I- and T-section shapes, with the remaining beams of rectangular cross section. None of the R/SFRC beams have conventional shear reinforcement (stirrups). Twenty three are prestressed and six have hybrid fibre reinforcement (passive and prestress). The test specimens used in this paper to test the design models are presented in Table 3.

Table 4 shows the intervals of values (minimum and maximum) of the database for the model parameters, demonstrating to cover a large spectrum of R/SFRC beams possible to find in real applications. In the analysis undertaken nine equal intervals of $10^{\circ}$ were used $(n \Delta \varphi=9)$.

The results of the analysis of the ISM applied to the database are shown in Fig. 8, together with the results of the MC2010_EEN and MC2010_MCFT approaches, described in Section 2. In all the analysis performed unit values were used for the safety factors, and average values were adopted for the material properties. The higher safety and smaller dispersion of the predictions obtained with the developed ISM is visible. Furthermore, the use of Eq. (5) in the MC2010_EEC and MC2010_MCFT approaches when the $f_{R i}$ are not available seems reliable. Excluding specimens that do not have data for $f_{R i}$ (which reduces the number of beams to 98 and 81 for the MC2010_EEN and the MC2010_MCFT models, respectively), the average and COV values of $\lambda$ are 1.32 and $24.5 \%$ for the MC2010_EEN model, and 1.35 and $26.7 \%$ for the 
MC2010_MCFT. Thus, the predictive capacity of using Eq. (5) does not significantly alter the conclusions.

The values of $\lambda$ were also evaluated according to an adapted version of the Demerit Points Classification $(D P C)$ proposed by Collins [50], where a penalty (PEN) is assigned to each range of $\lambda$ parameter according to Table 5 , and the total of penalties determines the performance of the proposal. The results are presented in Table 6 , where it is observed that the ISM registered a total penalty of 53 points, compared to 89 and 86 points for MC2010_EEN and MC2010_MCFT models, respectively.

\section{Conclusions}

In this work an innovative approach, herein denoted by "Integrated Shear Model - ISM", was developed for predicting the shear capacity of SFRC elements flexurally reinforced with conventional steel bars or tendons. The model has the potential of being adapted for cement based materials reinforced with other type of fibres, as long as the fibre pull-out constitutive law is evaluated appropriately. The model integrates the following main parts: fibre orientation profile for determining the number of fibres through the cross-section in discrete intervals of fibre orientation; the fibre pull-out constitutive law $\left(F_{f u k}\left(w_{u}\right)\right)$ according to the unified variable engagement model, which considers the relevant phenomena influencing the fibre reinforcement mechanism; and the modified compression field theory for the evaluation of the crack width at the shear failure stage of the critical diagonal crack $\left(w_{u}\right)$ and application of the determined $F_{f u k}\left(w_{u}\right)$ relationship.

A database comprising 122 SFRC beams was assembled for evaluating the performance of the ISM. The predictive performance of the ISM was also compared with that of two approaches set out in the Model Code 2010, one where the contribution of fibres is obtained through the value of the ultimate residual tensile strength of FRC $\left(f_{F t u}\right)$, herein designated as MC2010_EEN, and the other based on the MCFT approach, was demonstrated to perform well when compared with the test data and with the MC2010 approaches. 
For evaluating and comparing the performance of each model, the average test to model prediction ratio $(\lambda)$ and its coefficient of variation $(\mathrm{CoV})$ were determined. The average and $\mathrm{CoV}$ values for the proposed model are 1.12 and $16.6 \%$, respectively, while for the MC2010_EEN model and MC2010_MCFT model the averages and CoVs were 1.32 and 23.4\% and 1.32 and $24.2 \%$, respectively. The performance of the ISM was further compared to the MC2010 models by using an adapted version of the Demerit Points Classification (DPC) concept, with the higher performance of the developed approach demonstrated.

\section{Acknowledgements}

The authors wish to acknowledge the grant SFRH/BSAB/114302/2016 provided by FCT and the Australian Research Council grant DP150104107, as well as the support provided by the UNSW for the research activities carried out under the status of Visiting Professorial Fellow for the first author. The support of the FCT through the project PTDC/ECM-EST/2635/2014 is also acknowledged.

\section{References}

[1] Batson, G.; Jenkins, E.; and Spatney, R., "Steel Fibers as Shear Reinforcement in Beams," ACI journal, Proceedings, 69(10), 1972: 640-644.

[2] Lim DH, Oh BH. Experimental and theoretical investigation on the shear of steel fibre reinforced concrete beams. Engineering Structures 1999; 21(10): 937-44.

[3] Barragán BE. Failure and toughness of Steel Fiber Reinforced Concrete under tension and shear. PhD dissertation. Universitat Politecnica de Catalunya, Barcelona, Spain; 2002.

[4] Kwak Y-K, Eberhard MO, Kim W-S, Kim J. Shear strength of steel fiber-reinforced concrete beams without stirrups. ACI Structural Journal 2002;99(4):530-8.

[5] Rosenbusch J, Teutsch M. Shear design with- method. Proceedings of the RILEM TC 2003:105-17. 
[6] Minelli F. Plain and fiber reinforced concrete beams under shear loading: structural behaviour and design aspects. $\mathrm{PhD}$ dissertation. University of Trento, Italy; 2005.

[7] Bertozzi A, Reggia A. Steel fibers for the minimum shear reinforcement of the beams. MS thesis. University of Brescia, Brescia, Italy; 2006.

[8] Minelli F, Plizzari, GA, Vecchio FJ. Influence of steel fibers on full-scale RC beams under shear loading. In: Carpinteri A, Pietro G, Guieppe F, Plizzari, editors. Fracture Mechanics of Concrete Structures - High Performance Concrete, Brick-Masonry and Environmental Aspects. London, Taylor and Francis; 2007, p. 1523-31.

[9] Conforti A. Variable truss model for the shear design of fibre reinforced concrete beams: experimental and analytical study”. MS thesis. University of Brescia, Brescia; 2008.

[10] Greenough T, Nehdi M. Shear behavior of fiber-reinforced self-consolidating concrete slender beams. ACI Materials Journal 2008;105(5): 468-77.

[11] Dinh HH, Parra-Montesinos, GJ, Wight, JK. Shear strength model for steel fiber reinforced concrete beams without stirrup reinforcement. ASCE Journal of Structural Engineering 2011;137(10):1039-1051.

[12] Aoude H, Belghiti M, Cook WD, Mitchell D. Response of steel fiber-reinforced concrete beams with and without stirrups. ACI Structural Journal 2012;109(3):359-68.

[13] Conforti A, Minelli F, Plizzari GA. Wide-shallow beams with and without steel fibres: a peculiar behaviour in shear and flexure. Composites Part B Engineering 2013;51:282-90.

[14] Conforti A. Shear behavior of deep and wide-shallow beams in fiber reinforced concrete. PhD dissertation. Università degli Studi di Brescia, Brescia, Italy; 2014.

[15] Singh B, Jain K. Appraisal of steel fibers as minimum shear reinforcement in concrete beams. ACI Structural Journal 2014;111(5):1191-202.

[16] Jain K, Singh B. Investigation of steel fibres as minimum shear reinforcement. Proceedings of the Institution of Civil Engineers - Structures and Buildings 2014;167(5):285-99. 
[17] Jain K, Singh B. Deformed steel fibres as minimum shear reinforcement - a comparative appraisal. Magazine of Concrete Research 2014b;66(22):1170-82.

[18] Cuenca E. On Shear behavior of structural elements made of steel fiber reinforced concrete. Springer International Publishing; 2015.

[19] Al-lami K. Experimental Investigation of Fiber Reinforced Concrete Beams. MSc thesis. Portland State University, Portland, Oregon, USA; 2015.

[20] Soetens T. Design models for the shear strength of prestressed precast steel fibre reinforced concrete girders. PhD dissertation. Gent University, Belguim; 2015.

[21] Amin A, Foster SJ. Shear strength of steel fibre reinforced concrete beams with stirrups. Engineering Structures 2016;111:323-32.

[22] Jain K, Singh B. Deformed steel fibres as minimum shear reinforcement - An investigation, Structures 2016;7:126-37.

[23] Conforti A, Minelli F, Plizzari GA. Influence of width-to-effective depth ratio on shear strength of reinforced concrete elements without web reinforcement. ACI Structural Journal 2017;114(4):995-1006.

[24] Ortiz-Navas F, Navarro-Gregori J., Leiva-Herdocia GE, Serna-Ros P, Cuenca E. An experimental study on the shear behaviour of reinforced concrete beams including macrosynthetic fibres, Construction and Building Materials, 2018 (in press).

[25] Soltanzadeh F, Barros JAO, Santos RFC. High performance fiber reinforced concrete for the shear reinforcement: experimental and numerical research. Construction and Building Materials 2015;77: 94-109.

[26] Adebar, P, Mindess, S, St.-Pierre, D, and Olund, B. Shear Tests of Fiber Concrete Beams without Stirrups ACI Structural Journal, 1997; 94,(1),: pp. 68-76

[27] Foster SJ. Design of FRC beams for shear using the VEM and the draft model code approach. Chapter 12 In: fib Bulletin 57, International Federation for Structural Concrete fib, Lausanne, Switzerland; 2010, p. 195-201. 
[28] Heek, P, Look, K, Minelli, F, Mark, P, and Plizzari, G. Datenbank für querkraftbeanspruchte, Stahlfaserbetonbauteile: Bewertung der Bemessungsansätze nach DAfStb-Richtlinie und fib Model Code 2010, Ernst \& Sohn Verlag für Architektur und technische Wissenschaften GmbH \& Co. KG, Berlin. Beton- und Stahlbetonbau 2017; 112(3): 144-154.

[29] Foster SJ, Agarwal A, Amin A. Design of SFRC beams for shear using inverse analysis for determination of residual tensile strength. Structural Concrete 2018;19:129-140.

[30] Cuenca, E, Conforti, A, Minelli, F, Plizzari, GA, Gregori, JN, and Serna, P. A materialperformance-based database for FRC and RC elements under shear loading, Materials and Structures 2018; 51(11): 1130-1137

[31] Model Code 2010. fib Model Code for Concrete Structures 2010. International Federation for Structural Concrete (fib). Ernst \& Sohn, Berlin, Germany; 2013.

[32] di Prisco, M., Plizzari, G., Vandewalle, L., "MC2010: Overview on the shear provisions for FRC. Chapter 4 In: fib Bulletin 57, International Federation for Structural Concrete fib, Lausanne, Switzerland; 2010, p. 61-75.

[33] Moraes-Neto BN. Punching behaviour of flat slabs of steel fibre reinforced concrete submitted to symmetric loading. PhD dissertation. Universidade de Brasília, Brasília, Brazil; 2013.

[34] Moraes-Neto BN, Barros JAO, Melo GSSA. A model for the prediction of the punching resistance of steel fibre reinforced concrete slabs centrically loaded. Construction and Building Materials 2013;46:211-223.

[35] Amin A, Foster SJ, Muttoni A. Derivation of the $\sigma-\mathrm{w}$ relationship for SFRC from prism bending tests". Structural Concrete 2015;16(1):93-105.

[36] EN 14651. Test method for metallic fibre concrete-measuring the flexural tensile strength (limit of proportionality (LOP), residual). European Committee for Standardization; 2007: p. 17. 
[37] Vandewalle L, et al. Test and design methods for steel fibre reinforced concrete: $\sigma-\varepsilon$ design method - Final Recommendation. Materials and Structures 2003;36:560-567.

[38] UNI 11039. Steel Fiber Reinforced Concrete-Part I: Definitions, Classification Specification and Conformity_-Part II: Test Method for Measuring First Crack Strength and Ductility Indexes. Italian Board for Standardization: Rome, Italy; 2003.

[39] Baghi H., Barros JAO. Design Oriented Approach to Predict Shear Strength of Reinforced Concrete Beams. Structural Concrete, 2018; 19(1): 98-115.

[40] Oliveira FL. Design-oriented constitutive model for steel fiber reinforced concrete. $\mathrm{PhD}$ dissertation. Department of Project and Construction Engineering, Polytechnic University of Catalonia, Catalonia, Spain; 2010.

[41] Ng TS, Htut TNS, Foster SJ. Fracture of steel fibre reinforced concrete - the unified variable engagement model. UNICIV Report R-460, The University of New South Wales, UNSW Sydney, Australia; 2012.

[42] Ng TS, Foster SJ, Htet ML, Htut TNS. Mixed mode fracture behaviour of steel fibre reinforced concrete. Materials and Structures 2014;47:67-76.

[43] Bentz EC, Vecchio FJ, Collins MP. Simplified modified compression field theory for calculating shear strength of reinforced concrete elements. ACI Structural Journal 2006; 103:614-624.

[44] Krenchel H. Fibre spacing and specific fibre surface. In: Neville A, editor. Fibre reinforced cement and concrete, UK: The Construction Press, 69-79; 1975.

[45] Htut TNS. Fracture processes in steel fibre reinforced concrete. PhD dissertation. School of Civil and Environmental Engineering, The University of New South Wales, UNSW Sydney, Australia; 2010.

[46] Lee GG, Foster SJ. Behaviour of steel fibre reinforced mortar in shear I: Direct shear testing. UNICIV Report No. R-444. The University of New South Wales, UNSW Sydney, Australia; 2006. 
[47] Lee GG, Foster SJ. Behaviour of steel fibre reinforced mortar in shear II: Gamma ray imaging. UNICIV Report No. R-445. The University of New South Wales, UNSW Sydney, Australia; 2006.

[48] Lee GG, Foster SJ. Behaviour of steel fibre reinforced mortar in shear III: Variable engagement model II. UNICIV Report No. R-448. The University of New South Wales, UNSW Sydney, Australia; 2007.

[49] Foster SJ. The application of steel-fibres as concrete reinforcement in Australia: from material to structure. Materials and Structures 2009; 42(9): 1209-1220.

[50] Collins MP. Evaluation of shear design procedures for concrete structures. A Report prepared for the CSA technical committee on reinforced concrete design; 2001. 


\section{List of Figures}

Fig. 1 - Physical meaning of the variables of Eqs. (10) and (11) [31].

Fig. 2 - Representation of the variables for the simulation of the contribution of the flange of $\mathrm{T}$ or I cross section shape beam for its shear capacity.

Fig. 3 - Schematic representation of the proposed approach for the contribution of fibres bridging the CDC: a) relevant variables and concept of of $F_{f u k}\left[w_{u v}\left(w_{u}\right)\right]$; b) to f) example where the interval of fibre orientation domain was decomposed in four equal intervals of $25^{\circ}$ of amplitude - contribution of fibre reinforcement with orientation in the: b) full interval $\left(\left[0^{\circ}-90^{\circ}\right]\right)$, c) $\left[0-22.5^{\circ}\left[\right.\right.$, d) $\left[22.5^{\circ}-45^{\circ}\left[\right.\right.$, e) $\left[45^{\circ}-67.5^{\circ}\left[\right.\right.$, and f) $\left[67.5^{\circ}-90^{\circ}\right]$.

Fig. 4 - Cross section decomposed in three different domains of fibre orientation [44].

Fig. 5 - Fibre orientation profile.

Fig. 6 - Kinematics of fibre pull-out according to the UVEM.

Fig. 7 - Graphical outputs of the software applied to the NSC3-FRC1 R/SFRC beam tested by

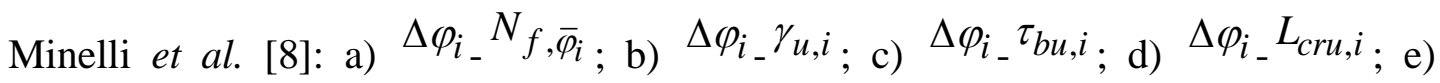
$\Delta \varphi_{i_{-}} P_{\bar{\varphi}_{i}}^{F P C L}\left(w_{u}\right)_{; \mathrm{f})} \Delta \varphi_{i_{-}} P_{\bar{\varphi}_{i}}^{F P C L}\left(w_{u}\right) \cdot N_{f, \bar{\varphi}_{i}}$.

Fig. 8 - Test to model comparisons for shear strength: a) ISM; b) MC2010_EEN; c) MC2010_MCFT. 


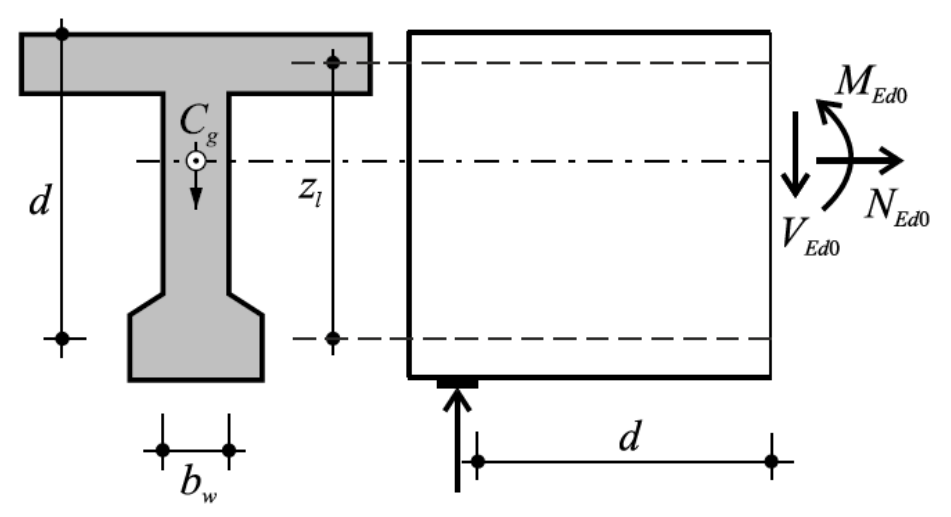

strain profile

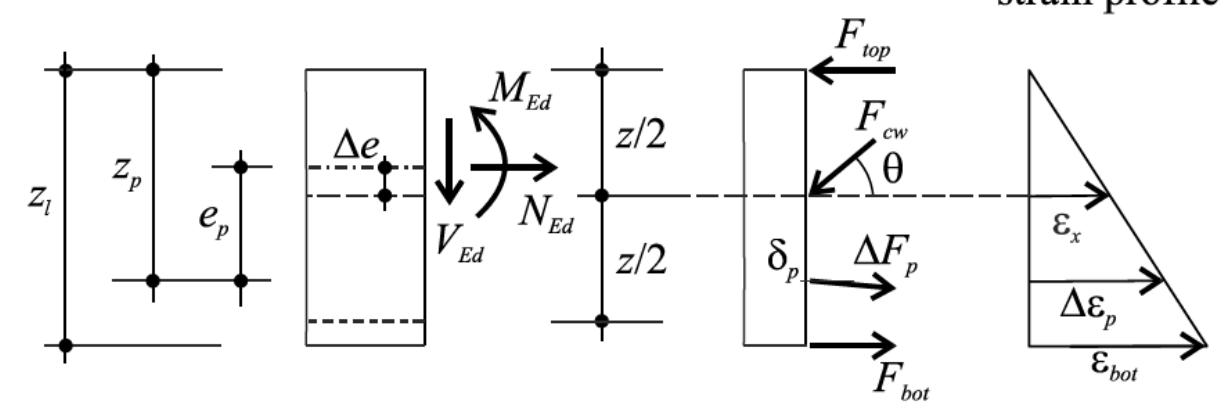

Fig. 1 - Physical meaning of the variables of Eqs. (10) and (11) [31]. 


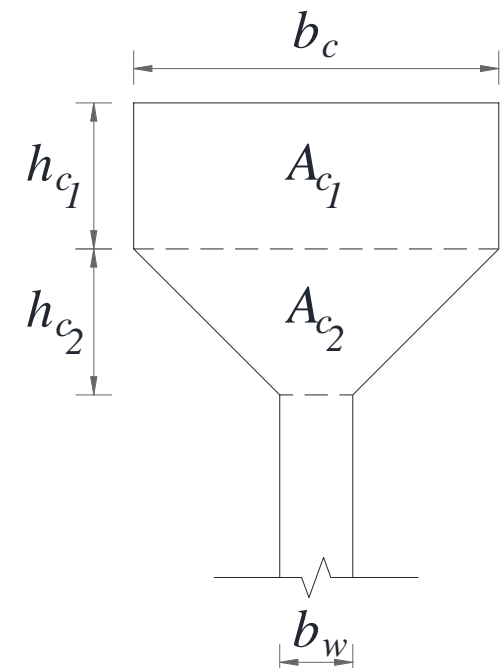

Contribution to the shear capacity due to the flange in T/I cross section beam

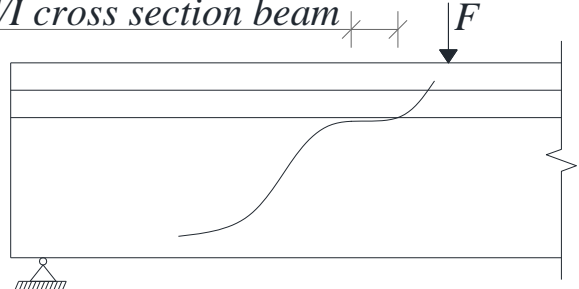

Fig. 2 - Representation of the variables for the simulation of the contribution of the flange of $\mathrm{T}$ or I cross section shape beam for its shear capacity. 


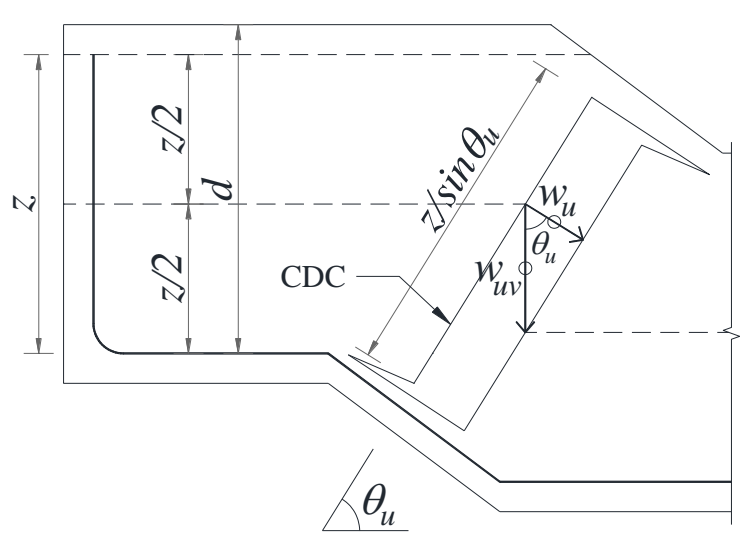

a)

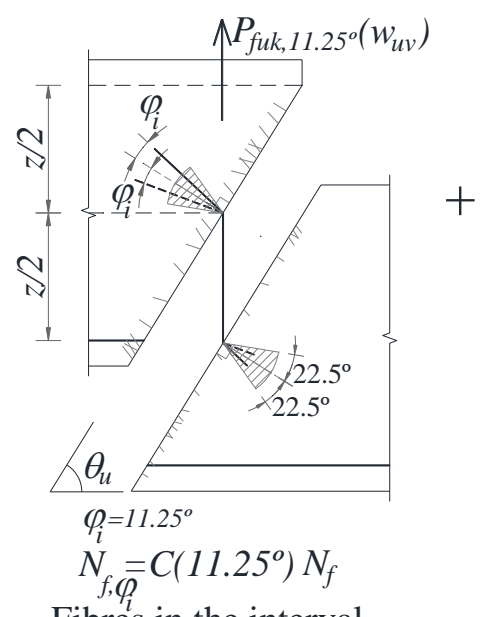

Fibres in the interval [0 $-22.5^{\circ}$ [

c)

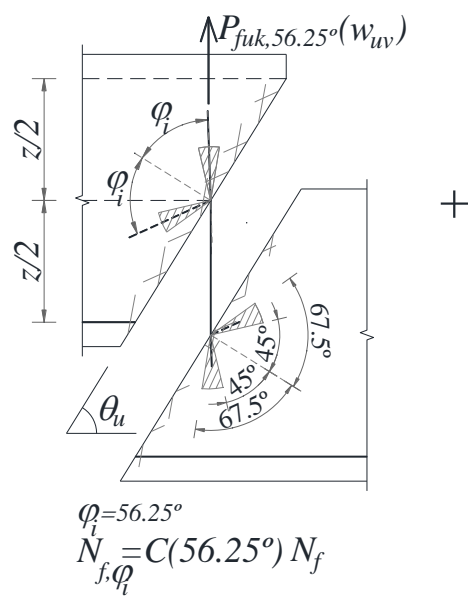

Fibres in the interval [45 $-67.5^{\circ}$ [

e)

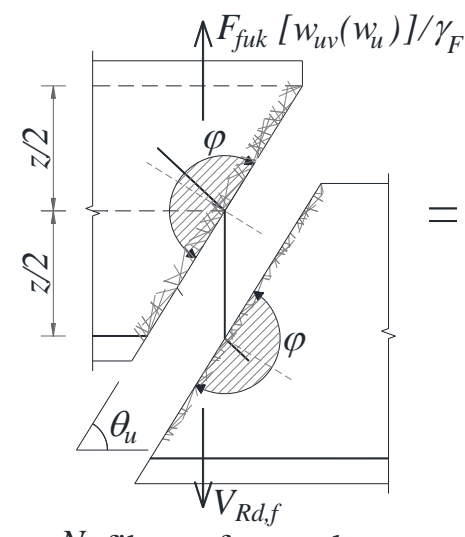

$N_{f}$ fibres of several orientations

b)

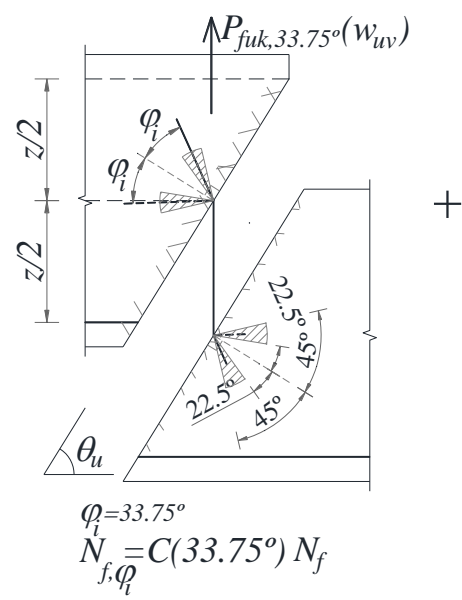

Fibres in the interval [22.5 $-45^{\circ}$ [

d)

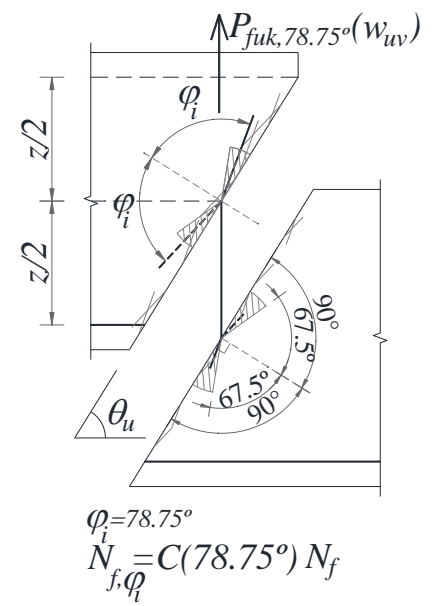

Fibres in the interval [67.5 $-90^{\circ}$ ]

f)

Fig. 3-Schematic representation of the proposed approach for the contribution of fibres bridging the CDC: a) relevant variables and concept of $F_{f u k}\left[w_{u v}\left(w_{u}\right)\right]$; b) to f) example where the interval of fibre orientation domain was decomposed in four equal intervals of $25^{\circ}$ of amplitude - contribution of fibre reinforcement with orientation in the: b) full interval $\left.\left(\left[0^{\circ}-90^{\circ}\right]\right), \mathrm{c}\right)\left[0-22.5^{\circ}[, \mathrm{d})\left[22.5^{\circ}-45^{\circ}[, \mathrm{e})\left[45^{\circ}-67.5^{\circ}\left[\right.\right.\right.\right.$, and f) $\left[67.5^{\circ}-90^{\circ}\right]$. 


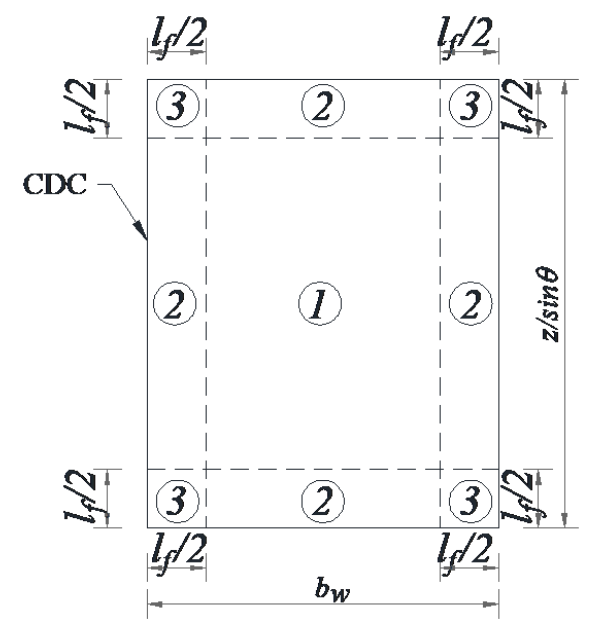

Fig. 4 - Cross section decomposed in three different domains of fibre orientation [44]. 


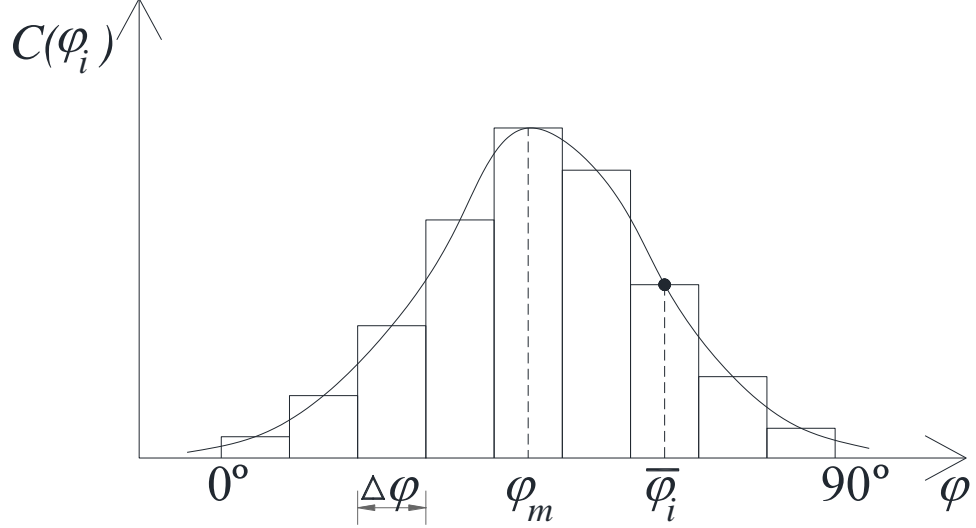

Fig. 5 - Fibre orientation profile. 

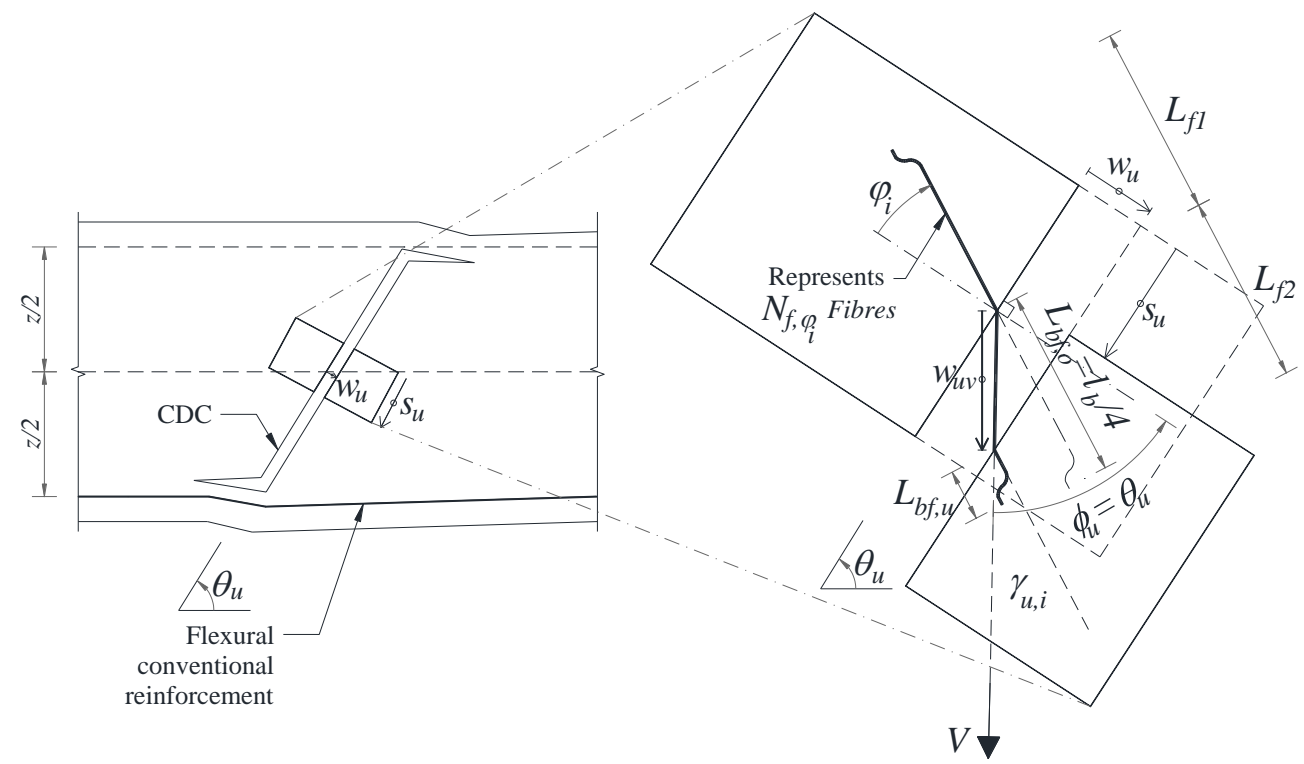

Fig. 6 - Kinematics of fibre pull-out according to the UVEM. 


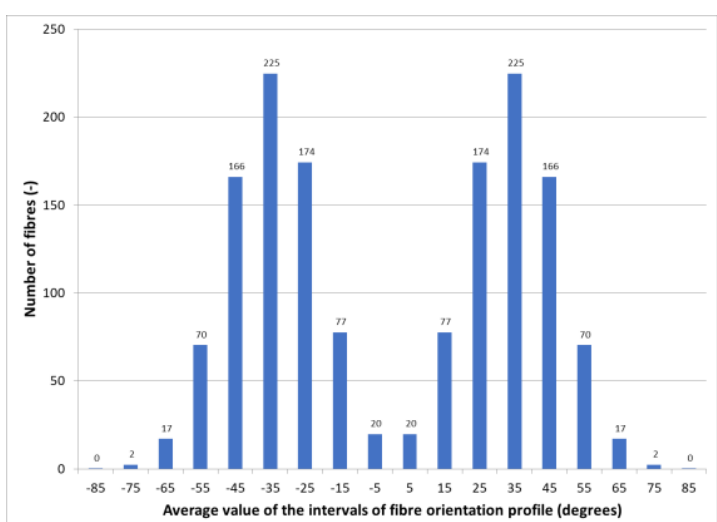

(a)

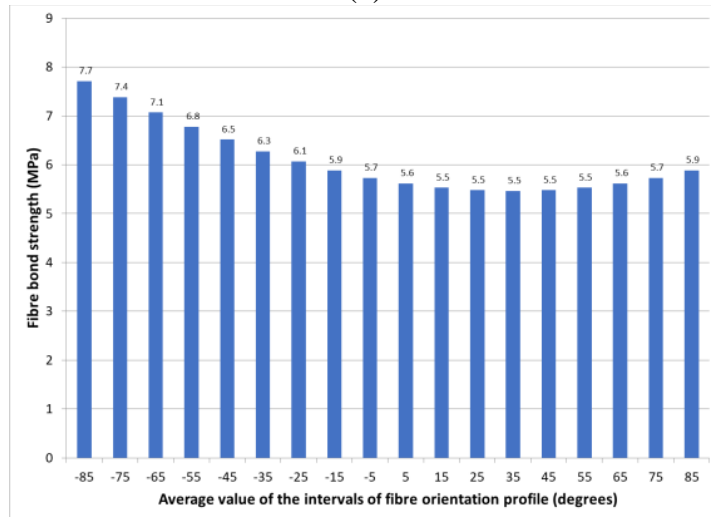

(c)

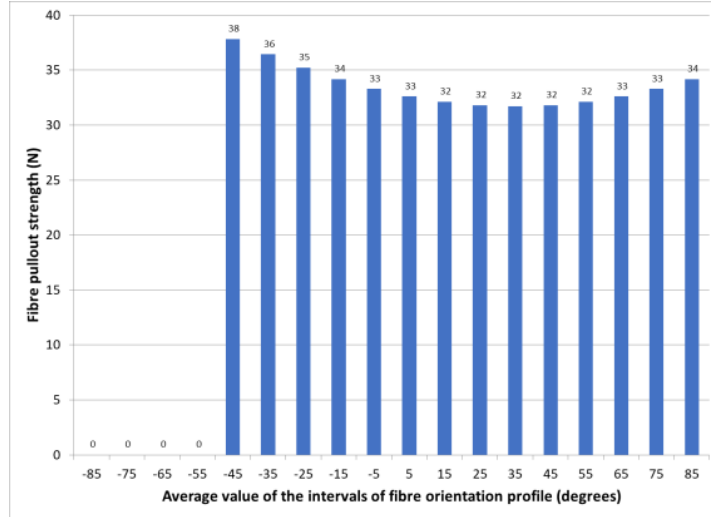

(e)

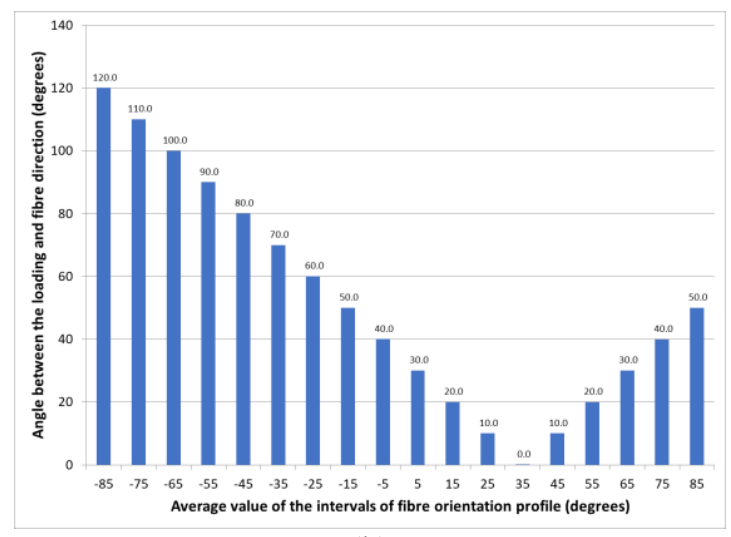

(b)

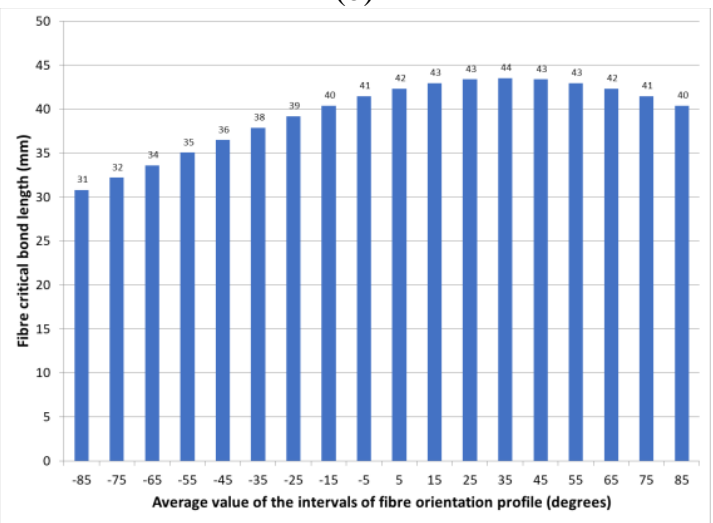

(d)

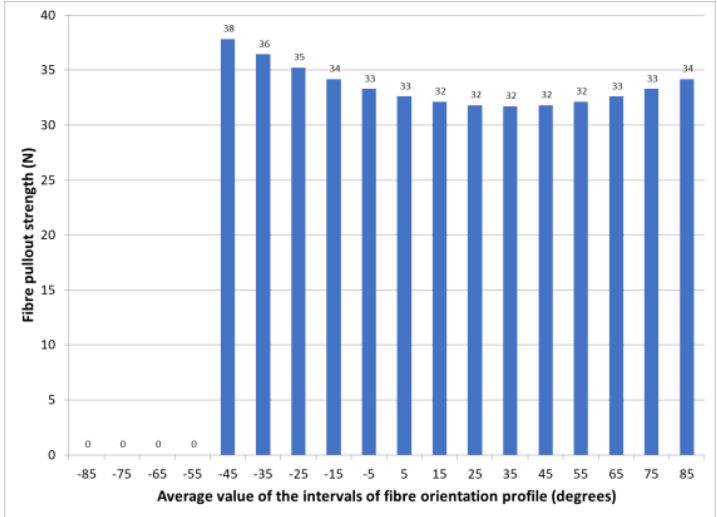

(f)

Fig. 7 -Graphical outputs of the software applied to the NSC3-FRC1 R/SFRC beam tested by Minelli et al. [8]: a) $\Delta \varphi_{i_{-}} N_{f, \bar{\varphi}_{i}}$; b) $\left.\left.\left.\Delta \varphi_{i_{-}} \gamma_{u, i} ; \mathrm{c}\right) \Delta \varphi_{i_{-}} \tau_{b u, i} ; \mathrm{d}\right) \Delta \varphi_{i_{-}} L_{c r u, i} ; \mathrm{e}\right) \Delta \varphi_{i_{-}} P_{\bar{\varphi}_{i}}^{F P C L}\left(w_{u}\right)_{\text {;f) }} \Delta \varphi_{i_{-}} P_{\bar{\varphi}_{i}}^{F P C L}\left(w_{u}\right) \cdot N_{f, \bar{\varphi}_{i}}$. 


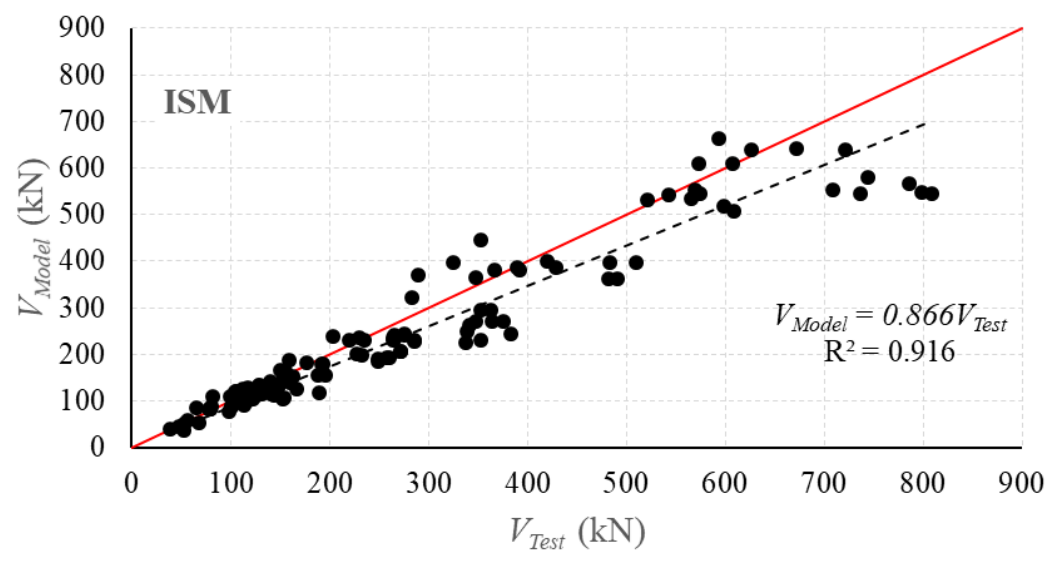

(a)

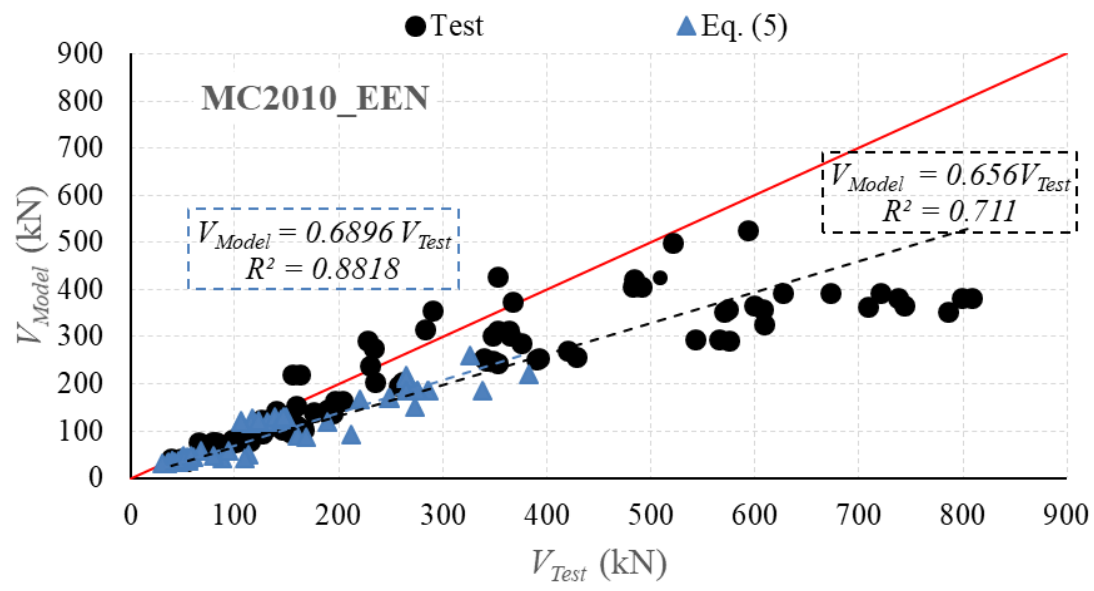

(b)

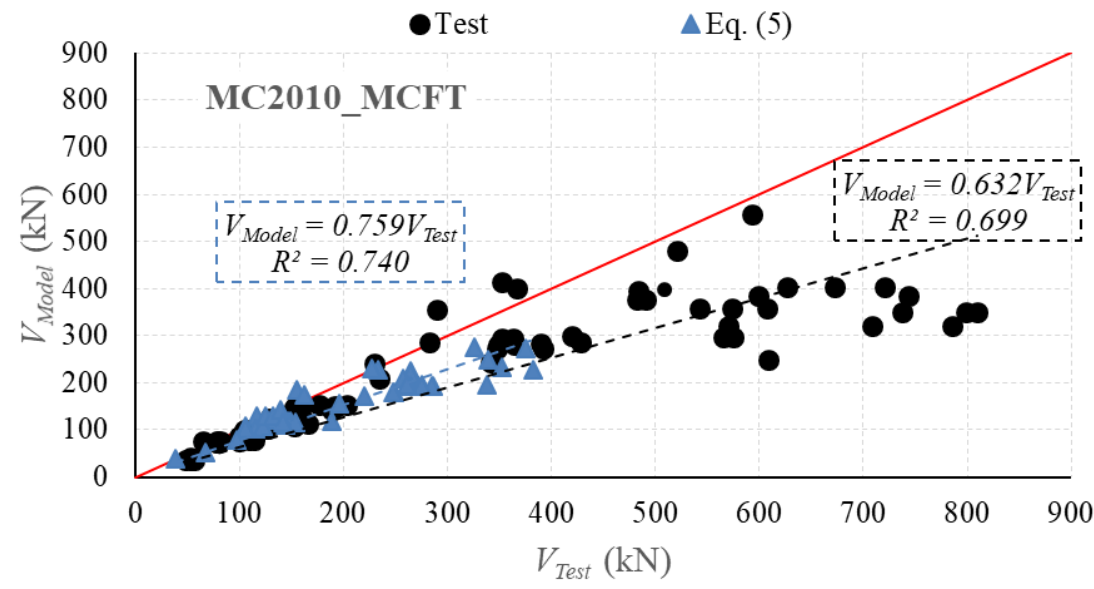

(c)

Fig. 8 - Test to model comparisons for shear strength: a) ISM; b) MC2010_EEN; c) MC2010_MCFT. 


\section{List of Tables}

Table 1: Values of $k_{b}$ (adapted from $\mathrm{Ng}$ et al. [41]).

Table 2: Results of the FDPC module applied to the NSC3-FRC1 R/SFRC beam tested by Minelli et al. [8].

Table 3: Steel fibre reinforced concrete (SFRC) beams failing in shear (and not limited by flexural strength)

Table 4 - Interval of values of the database for the model parameters.

Table 5. Adapted version of the Demerit Points Classification (DPC).

Table 6 - Prediction of $\lambda$ : classification of the proposals according to the modified version of the DPC. 
Table 1: Values of $k_{b}$ (adapted from $\mathrm{Ng}$ et al. [41]).

\begin{tabular}{|l|c|c|c|c|}
\hline \multirow{2}{*}{$\begin{array}{l}\text { Matrix } \\
\text { type }\end{array}$} & \multicolumn{4}{|c|}{ Fibre type } \\
\cline { 2 - 5 } & HE & HE-HS & S & C, FE and S-HS \\
\hline Mortar & 0.67 & 0.75 & 0.3 & 0.5 \\
\hline Concrete & 0.8 & 1.0 & 0.4 & 0.6 \\
\hline
\end{tabular}

NOTE: HE: Hooked ends steel fibres; HE-HS: Hooked ends steel fibres of high tensile strength ( $\left.\sigma_{f u}>1750 \mathrm{MPa}\right)$; C: Crimped steel fibres; FE: Flat ends steel fibres; S: Straight steel fibres; S-HS: Straight steel fibres of high tensile strength $\left(\sigma_{f u}>\right.$ $1750 \mathrm{MPa})$. 
Table 2: Results of the FDPC module applied to the NSC3-FRC1 R/SFRC beam tested by Minelli et al. [8].

\begin{tabular}{|c|c|c|c|c|c|c|c|c|c|c|}
\hline$\eta_{\varphi}$ & $F_{R E}\left(\eta_{\varphi}\right)$ & $\begin{array}{c}\varphi_{m} \\
\left({ }^{\circ} \mathrm{C}\right)\end{array}$ & $\begin{array}{c}\sigma\left(\varphi_{m}\right) \\
\left({ }^{\circ} \mathrm{C}\right)\end{array}$ & $\begin{array}{c}\phi_{u} \\
\left({ }^{\circ} \mathrm{C}\right)\end{array}$ & $\begin{array}{c}\gamma_{u}^{\max } \\
\left({ }^{\circ} \mathrm{C}\right)\end{array}$ & $\begin{array}{c}\bar{\sigma}_{f u} \\
(\mathrm{MPa})\end{array}$ & $N_{f}$ & $k_{b}$ & $\begin{array}{c}L_{b f, o} \\
(\mathrm{~mm})\end{array}$ & $\begin{array}{c}L_{C D C} \\
(\mathrm{~mm})\end{array}$ \\
\hline 0.82 & 1.0 & 34.56 & 13.08 & 35.00 & 125.00 & 792.0 & 1511 & 0.8 & 7.5 & 682.5 \\
\hline
\end{tabular}

\begin{tabular}{|c|c|c|c|c|c|c|c|c|c|}
\hline $\begin{array}{c}\bar{\varphi}_{i} \\
\left({ }^{\circ} \mathrm{C}\right)\end{array}$ & $\begin{array}{c}C\left(\bar{\varphi}_{i}\right) \\
(\%)\end{array}$ & $\begin{array}{c}N_{f, \bar{\varphi}_{i}} \\
(-)\end{array}$ & $\begin{array}{l}\gamma_{u, i} \\
\left({ }^{\circ} \mathrm{C}\right)\end{array}$ & $\begin{array}{l}w_{e v, i} \\
(\mathrm{~mm})\end{array}$ & $\begin{array}{c}\tau_{b u, i} \\
(\mathrm{MPa})\end{array}$ & $\begin{array}{c}L_{c r u, i} \\
(\mathrm{~mm})\end{array}$ & $\begin{array}{c}k_{u, i} \\
(-)\end{array}$ & $\begin{array}{c}P_{\bar{\varphi}_{i}}^{F P C L}\left(w_{u}\right) \\
(\mathrm{N})\end{array}$ & $\begin{array}{c}P_{\bar{\varphi}_{i}}^{F P C L}\left(w_{u}\right) \cdot N_{f, \bar{\varphi}_{i}} \\
(\mathrm{~N})\end{array}$ \\
\hline-85 & 1.2 & 0.2 & 120.0 & 688.4318 & 7.7 & 30.8 & 0.0 & 0.0 & 0.0 \\
\hline-75 & 15.6 & 2.4 & 110.0 & 24.6976 & 7.4 & 32.2 & 0.0 & 0.0 & 0.0 \\
\hline-65 & 112.7 & 17.0 & 100.0 & 4.9979 & 7.1 & 33.6 & 0.0 & 0.0 & 0.0 \\
\hline-55 & 465.3 & 70.3 & 90.0 & 1.6454 & 6.8 & 35.0 & 0.0 & 0.0 & 0.0 \\
\hline-45 & 1099.3 & 166.1 & 80.0 & 0.6708 & 6.5 & 36.5 & 0.4 & 37.8 & 6281.8 \\
\hline-35 & 1487.8 & 224.8 & 70.0 & 0.3028 & 6.3 & 37.9 & 0.4 & 36.4 & 8189.9 \\
\hline-25 & 1154.1 & 174.4 & 60.0 & 0.1420 & 6.1 & 39.2 & 0.4 & 35.2 & 6139.6 \\
\hline-15 & 512.9 & 77.5 & 50.0 & 0.0658 & 5.9 & 40.4 & 0.4 & 34.2 & 2647.1 \\
\hline-5 & 130.4 & 19.7 & 40.0 & 0.0285 & 5.7 & 41.4 & 0.4 & 33.3 & 656.0 \\
\hline 5 & 130.4 & 19.7 & 30.0 & 0.0106 & 5.6 & 42.3 & 0.4 & 32.6 & 642.5 \\
\hline 15 & 512.9 & 77.5 & 20.0 & 0.0029 & 5.5 & 43.0 & 0.4 & 32.1 & 2488.1 \\
\hline 25 & 1154.1 & 174.4 & 10.0 & 0.0003 & 5.5 & 43.4 & 0.4 & 31.8 & 5546.4 \\
\hline 35 & 1487.8 & 224.8 & 0.0 & 0.0000 & 5.5 & 43.5 & 0.4 & 31.7 & 7127.6 \\
\hline 45 & 1099.3 & 166.1 & 10.0 & 0.0003 & 5.5 & 43.4 & 0.4 & 31.8 & 5283.0 \\
\hline 55 & 465.3 & 70.3 & 20.0 & 0.0029 & 5.5 & 43.0 & 0.4 & 32.1 & 2257.2 \\
\hline 65 & 112.7 & 17.0 & 30.0 & 0.0106 & 5.6 & 42.3 & 0.4 & 32.6 & 555.1 \\
\hline 75 & 15.6 & 2.4 & 40.0 & 0.0285 & 5.7 & 41.4 & 0.4 & 33.3 & 78.4 \\
\hline 85 & 1.2 & 0.2 & 50.0 & 0.0657 & 5.9 & 40.4 & 0.4 & 34.2 & 6.3 \\
\hline
\end{tabular}


Table 3: SFRC beams failing in shear (and not limited by flexural strength).

\begin{tabular}{|c|c|c|}
\hline Reference & Specimen & $\begin{array}{c}\text { Determination of } \\
\text { Residual Tensile Strength }\end{array}$ \\
\hline Barragán [3] & $\begin{array}{l}\text { 20x45-SFRC-S1, 20x50-SFRC-S2, 20x60-SFRC-S1 } \\
\text { T10x50-SFRC-S1, T10x50-SFRC-S2, } \\
\text { T15x50-SFRC-S2 }\end{array}$ & Eq. (5) \\
\hline Kwak et al. [4] & FNB2-3 & Eq. (5) \\
\hline $\begin{array}{l}\text { Rosenbusch and } \\
\text { Teutsch [5] }\end{array}$ & $\begin{array}{l}\text { 3.1_1, 3.1_2, 20_50,3.1_3, 3.1_3 F2, 8_50, 3.2_1 } \\
\text { 10_50 F2, 15_50 F2 }\end{array}$ & $\begin{array}{l}\text { Eq. (14) (RILEM } \\
\text { Guidelines) }\end{array}$ \\
\hline Minelli [6] & $\begin{array}{l}\text { HSC-FRC1, I-Beam } 3 \text { DZ }{ }^{\#} \text { I-Beam } 4 \text { DZ } \\
\text { I-Beam }^{\#} \text { DZ I }{ }^{\#} \text {, I-Beam } 5 \text { DZ II }{ }^{\#} \text { I-Beam } 6 \text { DZ I } \\
\text { I-Beam } 6 \text { DZ II }^{\#} \text {, NSC1-FRC1, NSC2-FRC1, NSC3- } \\
\text { FRC1, HSC-FRC2 }\end{array}$ & $\begin{array}{l}\text { Eq. (14) (UNI } 11039 \text { and } \\
\text { RILEM) }\end{array}$ \\
\hline Bertozzi and Reggia [7] & $\begin{array}{l}\text { FRC-20 H50_1, FRC-40 H50_1, FRC-40 H50_2 } \\
\text { FRC-20 H100 }\end{array}$ & Eq. (5) \\
\hline Minelli et al. [8] & FRC-100 & $\begin{array}{l}f_{R 1} \text { and } f_{R 3} \text { from [8], and } f_{R 2} \\
\text { and } f_{R 4} \text { from Eq. (5) }\end{array}$ \\
\hline $\begin{array}{l}\text { Greenough and Nehdi } \\
{[10]}\end{array}$ & FRC & Eq. (5) \\
\hline Dinh et al. $[11]$ & $\begin{array}{l}\text { B18-3a, B18-3c, B18-3d, B27-1b, B27-4b } \\
\text { B18-2d, B18-5a }\end{array}$ & Eq. (14) (ASTM C1609) \\
\hline Aoude et al. [12] & $\mathrm{A} 0.5 \%, \mathrm{~A} 1 \%, \mathrm{~B} 0.5 \%, \mathrm{~B} 1 \%$ & Eq. (14) (ASTM C1609) \\
\hline Conforti et al. [13] & $\begin{array}{l}\text { W750 FRC25-1, W750 FRC25-2, W750 FRC35-1 } \\
\text { W750 FRC35-2, W1000 FRC25-1, W1000 FRC25- } \\
2 \\
\text { W1000 FRC35-1, W1000 FRC35-2 }\end{array}$ & Eq. (14) (EN 14651) \\
\hline Singh and Jain [15] & $\begin{array}{l}\text { DI-N-HO-35-0.75, DII-N-HO-35-0.75 } \\
\text { F-I-N-HO-35-1.50, G-I-N-HO-60-0.50 } \\
\text { G-II-N-HO-60-0.50, I-II-N-HO-60-1.00 } \\
\text { K-I-M-HO-35-0.75, K-II-M-HO-35-0.75 } \\
\text { P-II-M-HO-35-1.50, AA-II-M-HO-60-0.50 } \\
\text { N-I-M-HO-60-1.00, N-II-M-HO-60-1.00 }\end{array}$ & Eq. (14) (ASTM C1609) \\
\hline Jain and Singh [16] & $\begin{array}{l}\text { MH35-1, MH35-2, MH60-1, MH60-2, MC30-1 } \\
\text { MC30-2, MC60-1, MC60-2 }\end{array}$ & Eq. (14) (ASTM C1609) \\
\hline Cuenca [18] & $\begin{array}{l}\text { H1000 FRC50, H1000 FRC75, H1500 FRC50 } \\
\text { H1500 FRC75, H600_4 }{ }^{\#}, \text { H600_5 }, \text { H400h_6 } \\
\text { H400_7\# }, \text { H400_8 }, \text { H260_9 }, \text { H500 FRC75 }\end{array}$ & Eq. (14) (EN 14651) \\
\hline Al-lami [19] & B2-HS, B3-CS & Eq. (14) (ASTM C1609) \\
\hline Soetens [20] & $\begin{array}{l}3-2.5-[20 \mathrm{~A}]^{\#}, 1-2.5-[20 \mathrm{~B}]^{\#}, 2-2.5-[20 \mathrm{~B}]^{\#}, \\
\left.\left.1-2.5-[40 \mathrm{~A}]^{\#}, 2-2.5-[40 \mathrm{~A}]\right]^{\#}, 3-2.5-[40 \mathrm{~A}]\right]^{\#}, \\
\left.1-2.5-[40 \mathrm{~B}]^{\#}, 2-3.0-[40 \mathrm{~B}]{ }^{\#}, 1-2.5-[60]\right]^{\#}, 2-2.5-[60] \\
\#, 3-2.5-[60]^{\#}\end{array}$ & Eq. (14) (EN 14651) \\
\hline Amin and Foster [21] & B25-0-0-0, B50-0-0-0 & Eq. (14) (EN 14651) \\
\hline Jain and Singh [22] & H35-1, H60-2, C30-1, C30-2, C60-1, C60-2 & Eq. (14) (ASTM C1609) \\
\hline Conforti et al. [23] & $\begin{array}{l}\text { W105 FRC25-14, W210 FRC25-14, } \\
\text { W315 FRC25-14, W420 FRC25-14 } \\
\text { W525 FRC25-14, W630 FRC25-14 } \\
\text { W735 FRC25-14 }\end{array}$ & Eq. (5) \\
\hline Ortiz-Navas [24] & OAS1, OAS2, OBS1, OBS2 & Eq. (5) \\
\hline
\end{tabular}

Note: \# SFRC reinforced prestressed concrete beams. 
Table 4 - Interval of values of the database for the model parameters.

\begin{tabular}{|c|c|c|}
\hline \multirow{2}{*}{ Model parameter } & \multicolumn{2}{|c|}{ Value } \\
\hline & Minimum & Maximum \\
\hline \multicolumn{3}{|l|}{ Beam's geometry } \\
\hline$b_{w}(\mathrm{~mm})$ & 50 & 1000 \\
\hline$d(\mathrm{~mm})$ & 112.79 & 1440 \\
\hline \multicolumn{3}{|l|}{ Concrete properties } \\
\hline$f_{c m}(\mathrm{MPa})$, cylinders & 19.6 & 205.0 \\
\hline$d_{g}(\mathrm{~mm})$ & 5 & 25 \\
\hline$f_{R 1 m}(\mathrm{MPa})$ & 1.18 & 40.89 \\
\hline$f_{R 2 m}(\mathrm{MPa})$ & 0.82 & 41.20 \\
\hline$f_{R 3 m}(\mathrm{MPa})$ & 0.62 & 35.74 \\
\hline$f_{R 4 m}(\mathrm{MPa})$ & 0.49 & 29.44 \\
\hline \multicolumn{3}{|l|}{ Steel fibres } \\
\hline$V_{f}(\%)$ & 0.25 & 2.0 \\
\hline$l_{f}(\mathrm{~mm})$ & 13 & 60 \\
\hline$d_{f}(\mathrm{~mm})$ & 0.16 & 1.12 \\
\hline$\sigma_{f u}(\mathrm{MPa})$ & 966 & 3000 \\
\hline \multicolumn{3}{|c|}{ Passive longitudinal reinforcement } \\
\hline$A_{l}\left(\mathrm{~mm}^{2}\right)$ & $0^{*}$ & 3694 \\
\hline$\rho_{l}(\%)$ & $0^{*}$ & 4.35 \\
\hline$E_{l}(\mathrm{MPa})$ & \multicolumn{2}{|c|}{200000} \\
\hline$\varepsilon_{l y m}(\% o)$ & 2.0 & 2.78 \\
\hline \multicolumn{3}{|l|}{ Prestressed reinforcement } \\
\hline$A_{p}\left(\mathrm{~mm}^{2}\right)$ & $0^{* *}$ & 2520 \\
\hline$\rho_{p}(\%)$ & $0^{* *}$ & 6.23 \\
\hline$E_{p}(\mathrm{MPa})$ & \multicolumn{2}{|c|}{200000} \\
\hline$\varepsilon_{p y m}(\%)$ & 7.85 & 9.59 \\
\hline
\end{tabular}

*In case of beams exclusively reinforced with prestressed systems

${ }^{* *}$ In case of beams exclusively reinforced with passive reinforced systems 
Table 5. Adapted version of the Demerit Points Classification (DPC).

\begin{tabular}{|c|c|c|}
\hline$\lambda=V_{\text {test }} / V_{\text {model }}$ & Classification & Penalty (PEN) \\
\hline$<0.50$ & Extremely Dangerous & 10 \\
\hline$[0.50-0.70[$ & Dangerous & 5 \\
\hline$[0.70-0.85[$ & Reduced safety & 2 \\
\hline$[0.85-1.20[$ & Appropriate Safety & 0 \\
\hline$[1.20-2.0[$ & Conservative & 1 \\
\hline$\geq 2.0$ & Extremely Conservative & 2 \\
\hline
\end{tabular}


Table 6 - Prediction of $\lambda$ : classification of the proposals according to the modified version of the $D P C$.

\begin{tabular}{|c|c|c|c|c|c|c|}
\hline \multirow{2}{*}{$\lambda=V_{\text {tes }} / V_{\text {model }}$} & \multicolumn{3}{|c|}{ ISM } & \multicolumn{2}{c|}{ MC2010_EEN } & \multicolumn{2}{c|}{ MC2010_MCFT } \\
\cline { 2 - 7 } & N.Spec. & PEN & N.Spec. & PEN & N.Spec. & PEN \\
\hline$<0.50$ & 0 & 0 & 0 & 0 & 0 & 0 \\
\hline$[0.50-0.70[$ & 0 & 0 & 0 & 0 & 0 & 0 \\
\hline$[0.70-0.85[$ & 6 & 12 & 6 & 12 & 2 & 4 \\
\hline$[0.85-1.20[$ & 75 & 0 & 43 & 0 & 44 & 0 \\
\hline$[1.20-2.0[$ & 41 & 41 & 69 & 69 & 70 & 70 \\
\hline$\geq 2.0$ & 0 & 0 & 4 & 8 & 6 & 12 \\
\hline & 122 & $\mathbf{5 3}$ & 122 & $\mathbf{8 9}$ & 122 & $\mathbf{8 6}$ \\
\hline
\end{tabular}

